\author{
UNIVERSIDADE DE SÃO PAULO \\ FACULDADE DE ECONOMIA, ADMINISTRAÇÃO E CONTABILIDADE \\ DEPARTAMENTO DE ECONOMIA \\ PROGRAMA DE PÓS-GRADUAÇÃO EM ECONOMIA
}

\title{
Maior o Peso, Menor o Salário? \\ O impacto da obesidade no mercado de trabalho
}

Adriano Dutra Teixeira

Orientador: Profa. Dra. Maria Dolores Montoya Diaz

São Paulo

2016 
Prof. Dr. Marco Antonio Zago

Reitor da Universidade de São Paulo

Prof. Dr. Adalberto Américo Fischmann

Diretor da Faculdade de Economia, Administração e Contabilidade

Prof. Dr. Hélio Nogueira da Cruz

Chefe do Departamento de Economia

Prof. Dr. Márcio Issao Nakane

Coordenador do Programa de Pós-Graduação em Economia 


\title{
Maior o Peso, Menor o Salário? \\ O impacto da obesidade no mercado de

\author{
trabalho
}

\begin{abstract}
Dissertação apresentada ao Programa de Pós-Graduação em Economia do Departamento de Economia da Faculdade de Economia, Administração e Contabilidade da Universidade de São Paulo, como requisito parcial para a obtenção do título de Mestre em Ciências.
\end{abstract}

Orientador: $\operatorname{Prof}^{a}$. $\operatorname{Dr}^{a}$. Maria Dolores Montoya Diaz

\section{Versão Corrigida}

(versão original disponível na Biblioteca da Faculdade de Economia, Administração e Contabilidade)

São Paulo 
FICHA CATALOGRÁFICA

Elaborada pela Seção de Processamento Técnico do SBD/FEA/USP

Teixeira, Adriano Dutra

Maior o Peso, Menor o Salário? O impacto da obesidade no mercado de trabalho / Adriano Dutra Teixeira-- São Paulo, 2016.

$69 \mathrm{p}$.

Dissertação (Mestrado) - Universidade de São Paulo, 2016.

Orientador: Maria Dolores Montoya Diaz.

1. Obesidade 2. Mercado de trabalho 3. Econometria I. Universidade de São Paulo. Faculdade de Economia, Administração e Contabilidade. II. Título.

CDD - 616.398 


\section{Agradecimentos}

Agradeço a todos que participaram da conclusão desta etapa.

Agradecimentos especiais...

à Prof. Dolores, pela inestimável orientação de trabalho e de vida.

à minha família, pelo constante incentivo.

aos Prof. Fernando e Paula, pelas valiosas contribuições à pesquisa.

aos professores da FEA, por todos os ensinamentos.

aos colegas de turma, por tornarem-se eternos amigos.

aos alunos de Econometria I (grad.) e III (pós), pelas divertidas monitorias. 

“. it's a lot of little steps."

Peter A. Cohen 



\section{Resumo}

Com o aumento das taxas de obesidade, floresce o interesse sobre seus impactos no emprego. Diversas estratégias já foram empregadas na literatura de modo a quantificar estes efeitos, no entanto, há pouca evidência sobre os efeitos heterogêneos da obesidade, do salário e do tipo de ocupação (white e blue collar). Além disso, considerar a presença de endogeneidade da obesidade é prática cada vez mais demandada nas regressões de salário. Neste trabalho examinamos estas questões estimando o efeito do excesso de peso no salário com dados brasileiros provenientes da POF. A obesidade está associada a uma penalidade de 3,9\% (VI) a 9,1\% (MQO) no salário entre mulheres do grupo white collar. Mulheres do quantil inferior de salário são as mais penalizadas pela obesidade. Enquanto isso, estima-se que homens obesos white collar recebem em média de 7,2\% (VI) a 14,4\% (MQO) a mais que os não-obesos. O efeito positivo da obesidade é maior entre homens do quantil superior. A diversidade de resultados encontrados por grupos fortalece nossa estratégia de contemplar a heterogeneidade por tipo de ocupação.

Palavras-chaves: obesidade; salário; mercado de trabalho; heterogeneidade; endogeneidade 


\section{Abstract}

With the increasing rates of obesity, there is growing concern regarding its impact on employment. Several strategies have been employed in order to quantify these effects, however, there is little evidence of heterogeneous effects of obesity, wages and occupation (white and blue collar). Also, acknowledge the presence of endogeneity in obesity is increasingly demanded in wage regressions. We examine these issues estimating the effect of overweight on earnings by using Brazilian data from POF. Obesity is associated with a penalty of $3.9 \%(\mathrm{VI})$ to $9.1 \%(\mathrm{OLS})$ in earnings between white collar women. Women's lower quantile are the hardest hit by obesity. Meanwhile, it is estimated that overweight white collar men receive an average of $7.2 \%$ (VI) to $14.4 \%$ (OLS) higher than non-obese individuals. The positive effect of obesity is higher among the upper quantile men. The diversity of results found by groups strengthens our strategy to consider the heterogeneity by occupation.

Keywords: obesity; wages; labor market; heterogeneity, endogeneity 


\section{Sumário}

1 Introdução. . . . . . . . . . . . . . . . . . 11

2 Revisão da literatura . . . . . . . . . . . . . . . 15

2.1 Impacto da obesidade no salário . . . . . . . . . . . . . . . 15

2.2 Impacto da obesidade no emprego . . . . . . . . . . . . . . 17

2.3 Impacto da obesidade na seleção da ocupação $\ldots \ldots$. . . . . . . . . 19

2.4 Heterogeneidade da obesidade . . . . . . . . . . . . . . . 20

2.5 Heterogeneidade no salário . . . . . . . . . . . . . . . . . 23

2.6 Endogeneidade e Instrumentos . . . . . . . . . . . . . . . . . . . . 24

2.7 Discriminação por peso no trabalho . . . . . . . . . . . . . . . . . 29

3 Base de Dados . . . . . . . . . . . . . . . 33

4 Estratégias Empíricas . . . . . . . . . . . . . . . 35

5 Resultados. . . . . . . . . . . . . . . . . . . . 41

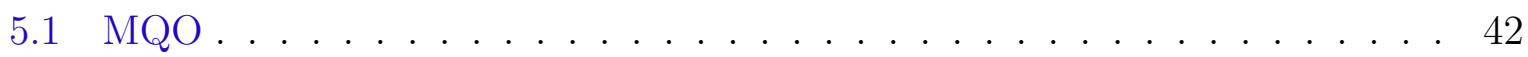

5.2 Regressão Quantílica . . . . . . . . . . . . . . . . 48

5.3 Variáveis Instrumentais . . . . . . . . . . . . . . . . . . 53

6 Considerações finais $\ldots \ldots \ldots \ldots \ldots \ldots$

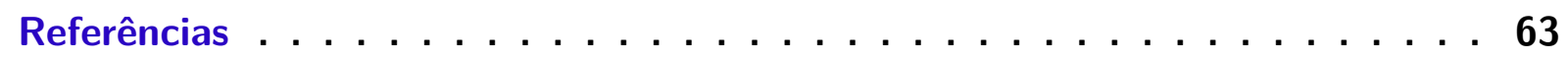





\section{Introdução}

A pesquisa insere-se no contexto de aumento das taxas de excesso de peso e obesidade. Em todo o mundo, estima-se que entre 1975 e 2014 a proporção de adultos com Índice de Massa Corporal (IMC) de $30 \mathrm{~kg} / \mathrm{m}^{2}$ ou mais subiu de 3,2\% para 10,8\% em homens, e de 6,4\% para 14,9\% em mulheres (NCD, 2016).

No Brasil, a obesidade vem rapidamente substituindo a desnutrição independentemente de gênero, região e estratos de renda da população adulta (MONTEIRO; CONDE; POPKIN, 2002). Constata-se que a prevalência da obesidade saltou de 11,1\% em 2002-2003 para 14,7\% em 2008-2009; e, somando a parcela que está em sobrepeso, vê-se que 49,0\% da população adulta apresenta excesso de peso. Hoje, os números mais recentes apontam que 50,8\% dos brasileiros estão acima do peso ideal, sendo 17,5\% obesos (VIGITEL, 2014).

Sabe-se que a obesidade é altamente associada ao aumento da morbidade e mortalidade por hipertensão, diabetes, dislipidemia e doenças cardiovasculares e renais (KOTCHEN, 2010) - o que configura um grave problema de saúde pública. Atualmente, a condição de sobrepeso e obesidade está ligada a mais mortes no mundo do que a condição de déficit de peso. Segundo a Organização Mundial da Saúde, $65 \%$ da população mundial vive em países onde o excesso de peso representa maior risco do que o déficit de peso. Estima-se que os custos totais das doenças relacionadas ao excesso de peso no Brasil chegam a US\$ 2,1 bilhões em apenas um ano (BAHIA et al., 2012). Deste modo, parte das consequências econômicas da obesidade consiste em custos mais altos em saúde que impõem externalidades negativas através de seguros de saúde (CAWLEY, 2015).

Com o aumento alarmante das taxas de obesidade, uma nova forma de segregação mostra-se presente: a discriminação por peso. Atualmente, a discriminação por peso é comparável às taxas de discriminação por cor e idade, especialmente entre as mulheres (CALIENDO; LEE, 2013). No mercado de trabalho, a discriminação por peso aparece sob a forma de salários reduzidos e diminuição das chances de emprego, sendo motivo de constante pesquisa.

Depois do artigo pioneiro de Register e Williams (1990) vários pesquisadores 
estudaram a relação entre o excesso de peso e seus efeitos nas condições de salário e emprego. Até o momento, parte considerável das evidências empíricas registra que, em nível individual, a obesidade e os resultados do mercado de trabalho estão negativamente relacionados, embora esta relação varie entre grupos. A evidência empírica para a Alemanha, por exemplo, diz que a obesidade é negativamente associada aos salários, para ambos os sexos (CAWLEY; GRABKA; LILLARD, 2005). Já na Dinamarca verificou-se um efeito negativo da obesidade e sobrepeso no emprego para mulheres, enquanto que para homens houve um efeito positivo (GREVE, 2007).

No Brasil, constata-se que o efeito do IMC sobre o salário assume uma relação significativa positiva para homens e negativa para mulheres. O padrão mantém-se ao estimar os efeitos na probabilidade emprego. A obesidade está associada a um acréscimo de probabilidade de emprego de 2,2 p.p. entre homens e uma redução na probabilidade de emprego de 4,3 p.p. entre mulheres (TEIXEIRA; DIAZ, 2012).

Em continuidade a estes trabalhos, nossa pesquisa busca incorporar questões cujo interesse internacional é crescente. A contribuição deste trabalho é no sentido de avançar no tema nos seguintes quesitos.

Primeiro, revisitaremos o efeito das medidas de obesidade no salário incluindo novas variáveis de controle e permitindo novas formas funcionais, de modo a contemplar efeitos não-lineares do IMC. A diversidade de resultados verificados entre grupos merece uma análise mais detalhada. Homens e mulheres têm obtido resultados heterogêneos, faz-se necessário averiguar os motivos e interpretar seus efeitos.

Segundo, é importante observar em que sentido os efeitos são diferentes entre tipos de ocupações, verificando, por exemplo, o que ocorre nos grupos de trabalho white collar e blue collar. Também com o objetivo de explorar a heterogeneidade do efeito no salário, incluímos a estimação por quantil buscando entender como se dá o efeito da obesidade ao longo da distribuição do salário.

Terceiro, em linha com a literatura de variáveis instrumentais, lidamos com a endogeneidade da medida de obesidade. Conforme tem sido verificado internacionalmente, 
há inúmeras razões para considerar que a medida de obesidade não é exógena (MORRIS, 2006). A endogeneidade pode ser consequência do viés de simultaneidade, já que a obesidade afeta os resultados no mercado de trabalho mas também os resultados no mercado de trabalho podem afetar a obesidade. Além disso, a endogeneidade pode ser decorrente de viés de variável relevante omitida, ou seja, fatores não observáveis que afetam tanto a obesidade quanto o mercado de trabalho. Outro canal de endogeneidade seria via erro de medida, caso o IMC for auto-reportado, por exemplo. Sendo assim, a busca de instrumentos relevantes para a obesidade individual faz-se necessária.

Salientamos, portanto, a relevância desta investigação tendo em vista a relativa escassez, até o momento, de estudos a este respeito no Brasil.

Este trabalho segue a seguinte estrutura. No Capítulo 2 revisitamos a literatura internacional sobre os efeitos da obesidade no emprego. Os artigos foram separados por tema e serviram de referencial para a escolha dos métodos aqui empregados. No Capítulo 3 descrevemos a base de dados e a seleção da amostra. No Capítulo 4 detalhamos as estratégias empíricas utilizadas e no Capítulo 5 colocamo-as em prática. O trabalho encerra no Capítulo 6 discutindo os resultados, limitações e ideias para pesquisas futuras. 



\section{Revisão da literatura}

A Revisão Bibliográfica está dividida em 7 seções. Em linhas gerais, buscamos apresentar um levantamento das evidências empíricas internacionais por assunto. Iniciamos apresentando os artigos sobre o impacto da obesidade: no salário, no emprego e na seleção da ocupação. A seguir, destacamos a importância de se considerar efeitos heterogêneos e nãolineares da obesidade no salário. Em seguida, apresentamos as estratégias já empregadas na literatura para lidar com a endogeneidade. Por fim, discutimos a discriminação por peso e as dificuldades de isolar os efeitos da discriminação por peso no mercado de trabalho.

\subsection{Impacto da obesidade no salário}

O trabalho de Register e Williams (1990) foi o primeiro a investigar a relação entre obesidade e salário. Usando dados cross-section dos EUA, o estudo reportou um efeito negativo de $12 \%$ da obesidade no salário-hora entre mulheres e um efeito positivo, mas não significativo, de 7\% entre homens. Depois deste trabalho, vários artigos foram publicados com dados de outros países.

Nos EUA, onde se encontra a maior parte das pesquisas publicadas no tema, parte substancial destes trabalhos usou os microdados da National Longitudional Survey of Youth (NLSY) (por exemplo, Averett e Korenman (1996), Averett e Korenman (1999), Cawley (2000), Cawley (2004), Gortmaker et al. (1993), Loh (1993), Majumder (2013), Pagan e Davila (1997) e Register e Williams (1990)). Destes, a maioria reporta que há um efeito negativo da obesidade no salário entre mulheres (por exemplo, Averett e Korenman (1996), Cawley (2000), Cawley (2004), Pagan e Davila (1997) e Register e Williams (1990)).

A magnitude do efeito encontrado entre mulheres, em muitos casos, é expressiva. Cawley (2004), por exemplo, reportou que um aumento de dois desvios-padrão no peso está associado a uma queda de $9 \%$ nos salários - efeito equivalente a um ano e meio de educação ou três anos de experiência. Há menos consenso, entretanto, nos resultados para homens. Loh (1993) e Majumder (2013) encontraram efeito positivo da obesidade no salário, já Pagan e Davila (1997) e Register e Williams (1990) não encontraram efeitos significativos. 
Avaliar penalidades no salário na Europa impõe dificuldades adicionais. No continente predominam estruturas mais rígidas de salário e uma parte considerável da força de trabalho pertence ao setor público (AVERETT, 2014). Na Dinamarca, por exemplo, o percentual de mulheres no setor público ultrapassa 50\% (GREVE, 2008). Ainda assim, várias pesquisas investigaram o efeito da obesidade no salário.

No Reino Unido, Sargent e Blanchflower (1994) analisaram a relação entre obesidade aos 16 anos e salários aos 23 anos. O estudo constatou uma relação inversa entre obesidade e salário em mulheres: as que estavam no top 10\% do IMC aos 16 anos, ganhavam 7,4\% a menos aos 23 anos, em comparação às não obesas. ${ }^{1}$ Para homens, não foram encontrados efeitos estatisticamente significativos. Em estudo posterior para o país, Morris (2006) observou um efeito negativo do IMC no salário-hora entre mulheres e positivo (nem sempre significativo) entre homens.

Na Finlândia, Johansson et al. (2009) avaliaram o efeito da obesidade no salário considerando o IMC e também outras medidas antropométricas, como circunferência da cintura e massa gorda. Verificou-se que uma unidade adicional de IMC está associada a um aumento de 0,1\% no salário-hora entre homens e a uma queda de 0,2\% entre mulheres, ambos, porém não significativos. O efeito da circunferência da cintura foi negativo e significativo entre mulheres ao nível de significância de 10\%; um aumento de $1 \mathrm{~cm}$ na circunferência da cintura está associado a uma redução de $0,1 \%$ no salário.

Na Dinamarca, Greve (2008) dividiu a amostra entre trabalhadores dos setores privado e público. Os resultados para homens do setor privado indicam uma relação entre IMC e salário de formato U-invertido, atingindo máximo em $28,5 \mathrm{~kg} / \mathrm{m}^{2}$. Entre mulheres do setor privado observou-se pouca variação no salário devido ao IMC. Não se encontrou efeitos estatisticamente significativos para trabalhadores do setor público.

Na Europa há ainda estudos para a Alemanha (CAWLEY; GRABKA; LILLARD, 2005) e Suécia (DACKEHAG; GERDTHAM; NORDIN, 2014) e existem também trabalhos com dados conjuntos para o continente, como o de Brunello e d'Hombres (2007), Garcia e

1 Vale dizer que o efeito negativo persistiu tanto no caso em que a mulher se manteve obesa aos 23 anos, quanto no caso em que ela mudou para a categoria não-obesa. 
Quintana-Domeque (2007) e Hildebrand e Kerm (2010).

\subsection{Impacto da obesidade no emprego}

Vimos na seção anterior uma das vias pelas quais a obesidade pode influenciar o emprego - i.é, através dos salários. Há, no entanto, outros caminhos que também devem ser considerados. Johansson et al. (2009) indagam, por exemplo, se o estado de saúde afetaria mais fortemente a probabilidade do indivíduo estar empregado do que afeta os salários.

De modo sistemático, Morris (2007) elenca quatro motivos pelos quais obesidade e emprego estão vinculados. Primeiro, obesidade gera efeitos no emprego. Isto porque obesidade, em muitos casos, debilita a saúde do indivíduo afetando sua produtividade e probabilidade de emprego; em outros casos, pode haver discriminação no trabalho contra a contratação de indivíduos obesos. Segundo, a falta de emprego gera efeitos na obesidade. Indivíduos desempregados são mais prováveis de consumir alimentos mais baratos, menos saudáveis e que engordam (CAWLEY, 2004). Terceiro, variáveis não observáveis (como preferência temporal) podem afetar tanto a obesidade quanto o emprego. Quarto, a obesidade pode ser medida com erros devido a fatores correlacionados com o emprego. Isto ocorre, por exemplo, se alguns grupos forem mais propensos a sub/sobrereportar seu status de obesidade. Tais argumentos justificam, portanto, o interesse empírico de avaliar a relação entre obesidade e emprego.

No trabalho de Johansson et al. (2009), foram realizadas estimativas de modelos Probit reportando os resultados dos efeitos marginais. Verificou-se que as medidas de obesidade adotadas (IMC, circunferência da cintura e massa gorda) tiveram um impacto negativo e significativo na probabilidade de emprego para mulheres. Um aumento de um quilograma de massa gorda está associado a uma queda de 0,5 p.p. na probabilidade de emprego para mulheres. Os resultados para homens são mistos: efeito positivo na especificação quadrática do IMC, efeito negativo na especificação com massa gorda, e não significativo nas demais especificações. 
Com dados da Dinamarca, Greve (2008) estudou a relação entre IMC e emprego por grupos de faixa etária. A probabilidade de estar empregado cresce com o IMC até atingir $26-27 \mathrm{~kg} / \mathrm{m}^{2}$ entre homens e $22-25 \mathrm{~kg} / \mathrm{m}^{2}$ entre mulheres. Após estes valores, a probabilidade de emprego diminui em todas as faixas etárias. Entre mulheres, os modelos Probit indicam que indivíduos nas categorias sobrepeso e obesidade tiveram efeitos negativos e significativos sobre o emprego, com efeito marginal de -0,039 e -0,085, respectivamente. Entre homens, a categoria sobrepeso apresentou efeito positivo (não significativo) sobre o emprego, com efeito marginal de 0,015 , enquanto que a categoria obesidade teve efeito marginal de $-0,028$.

Greve (2008) atribui duas razões para explicar o aumento da probabilidade de emprego entre homens em sobrepeso. Em primeiro lugar, o limiar de IMC que classifica homens em excesso de peso pode não representar corretamente a realidade do indivíduo. Vale lembrar que homens com boa condição física e alta massa muscular estão incluídos nesta categoria. Em segundo lugar, um maior IMC para homens pode representar sinal de força e poder, beneficiando homens em sobrepeso em algumas profissões - Cawley (2004) chama este efeito de "portly banker effect".

Através de Logit Multinomiais, Garcia e Quintana-Domeque (2007) analisaram, para países europeus, a razão entre a probabilidade do indivíduo estar desempregado com a probabilidade de trabalhar como um empregado (não-autônomo). De modo geral, as variáveis de obesidade (IMC, peso e dummy obeso) estiveram associadas a maiores probabilidades relativas de desemprego entre mulheres. Entre homens, verificou-se o resultado oposto: obesidade esteve vinculada a menores probabilidades relativas de estar desempregado. $^{2}$

Burkhauser e Cawley (2008) exploram o efeito de variáveis de obesidade na probabilidade do empregado reportar incapacidades no trabalho. Em linhas gerais, as três especificações implementadas obtiveram os seguintes resultados: (i) efeito positivo do IMC; (ii) efeito positivo da altura e negativo do peso; (iii) efeito positivo da TBF (total body fat)

$2 \quad$ Vale dizer que efeitos estatisticamente significativos foram encontrados em apenas 4 de 9 países: Bélgica, para mulheres; Finlândia, para homens, Itália, para mulheres; e Espanha, para mulheres. 
e negativo da FFM (free fat mass). Para homens brancos, em particular: (i) uma unidade extra de IMC está associada a um aumento de 0,12 p.p. na probabilidade de incapacidade no trabalho; (ii) um quilograma adicional está associado a um aumento de 0,04 p.p. na probabilidade de incapacidade no trabalho; (iii) uma unidade extra de TBF está associada a um aumento de 0,2 p.p. e unidade unidade extra de FFM está associada a um aumento de 0,13 p.p. na probabilidade de incapacidade no trabalho.

O trabalho de Burkhauser e Cawley (2008) revela, portanto, importantes informações sobre o efeito das medidas de obesidade no mercado de trabalho. Observaram-se diferentes efeitos a depender do tipo de massa corporal: TBF relaciona-se a efeitos adversos, enquanto que FFM associa-se a menores riscos. Isto reforça o argumento de que peso corporal e IMC ignoram a composição corporal e que medidas mais acuradas de obesidade devem ser também consideradas.

Caliendo e Gehrsitz (2014) foram os primeiros a tratar da relação entre obesidade e probabilidade de emprego via modelo semi-paramétrico. Verificou-se que a probabilidade de emprego possui comportamento em formato de U-invertido, atingindo máximo próximo a $23,5 \mathrm{~kg} / \mathrm{m}^{2}$ entre mulheres e $30 \mathrm{~kg} / \mathrm{m}^{2}$ entre homens.

\subsection{Impacto da obesidade na seleção da ocupação}

Além de impactos da obesidade no salário e na probabilidade de emprego, pode-se pensar em influências da obesidade no tipo de ocupação profissional. Ocupações podem ser preenchidas de maneira distinta entre obesos e não-obesos. Em um dos primeiros trabalhos no tema, Hamermesh e Biddle (1994) já haviam encontrado evidência de que pessoas de melhor aparência são selecionadas em empregos nos quais a aparência possa lhes ser mais vantajosa. Assim, seja por aparência, por produtividade, requisitos técnicos ou mesmo por discriminação, a obesidade pode ser um fator determinante no tipo de ocupação profissional.

Por meio de Logit Multinomiais, Garcia e Quintana-Domeque (2007) buscaram indícios de segregação no mercado de trabalho entre obesos, investigando se indivíduos 
obesos têm maior tendência a trabalhar como autônomos quando comparados com indivíduos não-obesos. Em 7 dos 9 países abordados pela pesquisa, encontrou-se RRRs (Relative Risk Ratios) superiores a um para ambos os sexos, o que indica que indivíduos obesos tendem a trabalhar mais como autônomos do que como empregados. ${ }^{3}$

A obesidade gera impactos na seleção da ocupação em níveis ainda mais detalhados. No trabalho de Pagan e Davila (1997) encontrou-se que homens obesos são subrepresentados em ocupações envolvendo funções administrativas, técnicas, vendas e produção. Mulheres obesas, por sua vez, são subrepresentadas em ocupações administrativas e técnicas, ficando concentradas em serviços de apoio administrativo e serviços gerais.

Tal pesquisa também discorre acerca de diferenças na ocupação por gênero. Enquanto que entre mulheres verificou-se uma penalidade no salário relacionada à obesidade, entre homens não se observou penalidades no salário em decorrência da obesidade - isto, aliás, corrobora a grande parte da literatura internacional. Os autores apresentam então evidências de que isto ocorre em parte porque homens obesos tendem a compensar possíveis penalidades vinculadas ao peso seja indo para ocupações onde eles são mais produtivos que os não-obesos, ou indo para ocupações onde eles recebem um prêmio por incorrer maiores riscos no mercado de trabalho. Assim, sob esta perspectiva, menores barreiras na mudança de ocupação ajudaria a explicar os resultados entre homens, enquanto que a discriminação no mercado de trabalho ajudaria a explicar os resultados entre mulheres.

\subsection{Heterogeneidade da obesidade}

Vimos nas seções anteriores que diferentes resultados foram obtidos acerca do impacto da obesidade no mercado de trabalho na literatura internacional. Além das especificidades regionais, um fator que pode influenciar para a ausência de um padrão nos resultados é o fato de que um comportamento não-linear está presente na relação saláriopeso - o que, caso não modelado corretamente, pode fornecer resultados e interpretações questionáveis.

3 Entre homens e mulheres, obteve-se resultados estatisticamente significativos na Grécia, Irlanda, Itália e Espanha. 
A pesquisa de Hildebrand e Kerm (2010) traz um exemplo ilustrativo que é recorrente nas estimações lineares. Enquanto que em mulheres verificou-se uma associação negativa entre IMC e salário, em homens não se observou qualquer relação estatisticamente significativa. O argumento aqui é que a ausência de estimativas estatisticamente significativas entre homens pode estar escondendo uma relação mais sofisticada. Por exemplo, se o salário for negativamente correlacionado tanto com baixos valores de IMC (indivíduos na categoria subpeso), quanto com altos valores de IMC (indivíduos na categoria obeso), estimações lineares podem sugerir equivocadamente a ausência de associação significativa. Neste caso, os autores estimaram então o modelo quadrático do IMC e encontraram uma relação estatisticamente significativa em formato de U-invertido.

O caso anterior serve para lembrar a importância da escolha da forma funcional adequada. É recente o interesse por formas funcionais alternativas à linear nos modelos de salário-peso. O artigo de Wada e Tekin (2010) foi o primeiro a incorporar o peso ao quadrado na regressão do salário. Possíveis não-linearidades também podem ser contempladas adicionando uma especificação com o IMC ao quadrado e especificações usando variáveis dummy indicativas da categoria de peso - subpeso, sobrepeso e obeso.

Uma limitação importante desta abordagem consiste em pressupor que o efeito começa onde o IMC é maior que $30 \mathrm{~kg} / \mathrm{m}^{2}$ e considerar que seu efeito é constante ao longo da categoria. Ocorre que na prática isto não acontece. Greve (2008), por exemplo, encontrou que entre mulheres a probabilidade de emprego é crescente até que o IMC atinja $22-25 \mathrm{~kg} / \mathrm{m}^{2}$, indicando que não apenas obesas, mas também mulheres em peso normal e em sobrepeso que situam-se acima desta faixa de IMC, têm menores chances de emprego.

Com objetivo de investigar estas questões, pesquisas mais recentes têm-se posicionado em favor de modelos que incorporem mais categorias de IMC de modo a permitir efeitos distintos no salário para diferentes intervalos de IMC. Outra alternativa seria estimar modelos semi-paramétricos em virtude da flexibilidade funcional que o método proporciona. Neste sentido, ao invés de pressupor uma forma funcional específica, o modelo semi-paramétrico estima uma forma funcional que se adequa aos dados. 
Com dados dos EUA, Gregory e Ruhm (2011) comparam os resultados obtidos via MQO linear, MQO quadrático no IMC e modelo semi-paramétrico. Para mulheres, MQOs linear e quadrático indicam uma relação negativa entre IMC e salário, independentemente do nível de IMC. Enquanto isso, o modelo semi-paramétrico aponta um aumento do salário até o IMC próximo a $23 \mathrm{~kg} / \mathrm{m}^{2}$ e uma queda brusca no salário logo em seguida. Para homens, o MQO linear apresenta o salário invariante ao IMC. O MQO quadrático, por sua vez, indica que o salário é máximo quando o IMC atinge $30 \mathrm{~kg} / \mathrm{m}^{2}$ enquanto que o modelo semi-paramétrico aponta pico próximo a $27 \mathrm{~kg} / \mathrm{m}^{2}$.

Estes casos servem para reforçar que mesmo os modelos paramétricos quadráticos possuem limitações. Ao prever que o salário assume seu valor máximo próximo a $30 \mathrm{~kg} / \mathrm{m}^{2}$, o modelo quadrático favorece a conjectura de que há uma penalidade no salário em decorrência da obesidade. No entanto, os resultados dos modelos semi-paramétricos contestam esta tese ao indicar que os salários começam a cair antes, em níveis inferiores de IMC.

Outros exemplos são os trabalhos de Shimokawa (2008), Hildebrand e Kerm (2010) e Caliendo e Gehrsitz (2014).

Com dados da China, as estimativas semi-paramétricas de Shimokawa (2008) apresentaram uma relação não-linear entre salário e peso. Verificou-se evidências de menores salários entre obesos, tanto em homens quanto em mulheres. Esta penalidade é acentuada a partir de $32 \mathrm{~kg} / \mathrm{m}^{2}$ entre homens, e a partir de $30 \mathrm{~kg} / \mathrm{m}^{2}$ entre mulheres.

Assim como Gregory e Ruhm (2011) fizeram para os EUA, Hildebrand e Kerm (2010) estimaram a relação salário-IMC através das formas linear, quadrática e semiparamétrica com dados da Europa. Estimações semi-paramétricas revelaram uma relação próxima à forma quadrática entre homens e próxima à linear entre mulheres. Apesar disso, aspectos interessantes omitidos nas formas linear e quadrática surgem na forma semi-paramétrica. ${ }^{4}$ Os autores produziram ainda testes de Razão de Verossimilhança

4 Entre homens, enquanto que a forma quadrática sugeriu salário máximo no IMC de $28 \mathrm{~kg} / \mathrm{m}^{2}$, a forma semi-paramétrica encontrou máximo no intervalo $24-31 \mathrm{~kg} / \mathrm{m}^{2}$, com penalidades no salário fora desta faixa. Entre mulheres, enquanto que a estimação linear sugeriu uma relação decrescente entre IMC e salário, a estimação semi-paramétrica apresentou um máximo próximo a $21 \mathrm{~kg} / \mathrm{m}^{2}$, havendo também uma penalidade no salário, em menor intensidade, entre indivíduos com baixo peso. 
para checar a hipótese nula de que os modelos semi-paramétricos são iguais aos modelos paramétricos considerados (linear e quadrático), todos os casos forneceram evidências para a rejeição.

Por fim, Caliendo e Gehrsitz (2014) avançam um passo importante ao separar as estimações em grupos de trabalho - white collar e blue collar -, com dados da Alemanha. É de se esperar, por exemplo, que a aparência física seja mais relevante entre ocupações white collar. Com efeito, salários entre mulheres white collar atingem máximo com IMC de $22 \mathrm{~kg} / \mathrm{m}^{2}$, decrescendo em seguida. Os resultados de mulheres blue collar assemelham-se aos resultados do modelo linear. Entre homens, não se observou evidências de que o IMC afeta o salário em ocupações white collar, tal efeito foi constatado em ocupações blue collar sobre a forma de penalidade ao subpeso. ${ }^{5}$

Gregory e Ruhm (2011), Hildebrand e Kerm (2010) e Caliendo e Gehrsitz (2014) valem-se de interpretações semelhantes para seus resultados. O fato de que o salário máximo reside em IMC próximo a $23 \mathrm{~kg} / \mathrm{m}^{2}$ ou inferior entre mulheres, e portanto ainda dentro da faixa saudável de IMC, é interpretado como evidência de um prêmio no salário em virtude da aparência física favorável, ao invés de uma penalidade oriunda de efeitos adversos da obesidade na saúde. Neste sentido, segundo a interpretação destes autores, o IMC se tornaria uma proxy para a aparência física estando sujeito a prêmios e penalidades no mercado de trabalho.

\subsection{Heterogeneidade no salário}

Até aqui, nota-se pela evidência empírica reportada, a presença de efeitos heterogêneos da obesidade no emprego entre homens e mulheres, e entre ocupações - white collar e blue collar.

Uma questão pertinente consiste na consideração de efeitos heterogêneos da obesi-

5 Teste de Razão de Verossimilhança apontou diferença significativa ao comparar as especificações semi-paramétrica e a quadrática entre mulheres white collar e homens blue collar. Tal teste não foi rejeitado ao comparar os modelos linear e semi-paramétrico entre mulheres blue collar e homens white collar. 
dade na distribuição do salário. Até agora, a literatura pouco avançou neste quesito. No entanto, esta é uma questão especialmente importante caso a obesidade afete o salário diferentemente nas partes inferior e superior da distribuição do salário. Assim, ao adotar a abordagem de regressão na média, podemos perder importantes informações que seriam reveladas na estimação quantílica.

Atella, Pace e Vuri (2008) foram os primeiros - e até o momento, únicos - a avaliar o impacto da obesidade em diferentes quantis de salário. O artigo constatou diferentes resultados entre os quantis avaliados, obtendo, por exemplo, efeito positivo de $2 \%$ do IMC no salário em homens para o grupo que recebe $75^{\circ}$ quantil e efeito negativo de $4 \%$ do IMC no salário em mulheres que recebem o quantil inferior ( $15^{\circ}$ quantil). Mais pesquisas são necessárias neste quesito.

\subsection{Endogeneidade e Instrumentos}

Explicar a alta correlação entre obesidade e os resultados no mercado de trabalho exige considerar os efeitos de causalidade e também possíveis efeitos de causalidade reversa. Em trabalho pioneiro sobre o tema, Register e Williams (1990) já levantavam a possibilidade de endogeneidade: "the obese may have such status [obesity] because of low earnings, to the extent that income level affects food and nutritional consumption behavior". De fato, além dos casos em que há viés de simultaneidade, a endogeneidade ainda pode ser decorrência de viés de variável relevante omitida ou via erro de medida. Portanto, há motivos suficientes para suspeitar que a obesidade não é exógena nos modelos de salário.

Diversas estratégias já foram aplicadas pela literatura internacional com o objetivo de lidar com a endogeneidade. Vamos separá-las aqui em três categorias.

Primeiro, alguns autores utilizaram uma medida prévia do peso corporal para lidar com o viés de determinação simultânea. Este expediente é baseado na hipótese de que o peso prévio é não-correlacionado com o erro da equação salário. A ideia é que se o salário causa variações no peso, usar uma medida prévia do peso deve reduzir o viés deste processo, principalmente se esta medida prévia foi coletada anteriormente à entrada do 
indivíduo no mercado de trabalho. Assim, as fontes de endogeneidade devem ser menos intensas ao se usar um valor prévio de medida corporal.

Este procedimento foi adotado por Averett e Korenman (1996), de modo que além de estimar relações entre a renda corrente e o IMC corrente (quando os indivíduos tinham entre 23 e 31 anos), também foram estimadas relações entre a renda corrente e o IMC de 7 anos antes. Ao usar o IMC prévio, obteve-se, especialmente entre mulheres, coeficientes ainda mais negativos na equação da renda - sugerindo a existência de um viés para cima gerado pela endogeneidade na relação entre IMC e renda correntes. Abordagem semelhante foi adotada por Gortmaker et al. (1993), Sargent e Blanchflower (1994), Cawley (2004), Wada e Tekin (2010) e Larose et al. (2016).

Segundo, outras pesquisas seguiram a estratégia de efeitos fixos. Parte destas usou comparações de irmãos para determinar se os resultados refletem a influência familiar (por exemplo, classe social) sobre o peso, ou se de fato se deve à relação entre peso e status econômico. Sendo assim, diferenciar as estimativas entre irmãos tem como objetivo reduzir muitos dos fatores não-observados genéticos e do ambiente. Conley e Glauber (2007) explicam em detalhes o procedimento. O modelo de efeitos fixos pode ser expresso da seguinte forma:

$$
Y_{i j}=X_{i j} \beta+a_{i}+u_{i j}
$$

sendo que $Y_{i j}$ é a variável resultado (salário ou renda) para o irmão $j$ na família $i, X$ é um vetor que contempla o peso corporal (ou IMC, ou outra medida antropométrica) e demais variáveis explicativas, e o termo de erro é dividido em dois componentes: $a_{i}$, o efeito fixo da família, e $u_{i j}$, o erro específico de cada irmão $j$ na família $i$. Ao diferenciar entre irmãos em cada família, o efeito fixo não-observado familiar é eliminado. Este método não elemina, contudo, os fatores que são específicos para cada irmão $j$ na família $i$, o que pode ser motivo de viés.

As estimativas de efeitos fixos de Conley e Glauber (2007) tiveram mesma direção das estimativas MQO. No entanto, na maioria dos modelos, encontrou-se diferenças sistemáticas entre os coeficientes MQO e de efeito fixo através de Testes de Hausman. Esta 
estratégia também foi adotada por Averett e Korenman (1996) usando irmãos de mesmo sexo e obteve resultados semelhantes às estimações usuais.

Outra parte da literatura usou o modelo de efeitos fixos individuais para eliminar a heterogeneidade invariante no tempo. A ideia é aproveitar a natureza longitudinal dos dados para expurgar efeitos fixos específicos do indivíduo. Tomando como hipótese que alguns fatores genéticos e não-genéticos são constantes no tempo, o método elimina portanto mais variação devido a fatores não-genéticos do que eliminaria ao se usar diferenças entre irmãos gêmeos ou irmãos de mesmo sexo. Cawley (2004) e Wada e Tekin (2010) usaram este procedimento e reportaram como resultado mudanças substanciais nas estimativas, eliminando a correlação negativa entre peso e salário para diversos grupos. ${ }^{6}$

Terceiro, o método de variáveis instrumentais é amplamente empregado como forma de lidar com a endogeneidade. A ideia consiste na busca de instrumentos relevantes para a medida antropométrica utilizada (peso ou IMC, por exemplo) - que sejam preditivos da obesidade do indivíduo mas completamente não-relacionados com os resultados no mercado de trabalho. Mais formalmente, procura-se variáveis que satisfaçam dois requisitos: (i) sejam correlacionadas com a medida antropométrica (relevância do instrumento) e (ii) ortogonais ao erro na equação do salário (exogeneidade do instrumento).

Medidas baseadas na área familiar são muito utilizadas como instrumentos para variáveis de nível individual. Cawley (2004) usou o IMC de um irmão como instrumento para o IMC individual. O autor argumenta que irmãos de mesmos pais compartilham ao menos metade de seus genes, o que garantiria uma forte correlação entre o IMC do indivíduo e o de seu irmão. Restaria então a tarefa mais complicada, expor que o erro da equação de salário do indivíduo é não-correlacionado com o IMC de seu irmão. Pode-se decompor este erro entre fatores genéticos e não-genéticos da seguinte forma:

$$
e_{i t}=G_{i t}+N G_{i t}+v_{i t}
$$

Sustentar a hipótese de exogeneidade do instrumento necessita, portanto, que o

6 Em Cawley (2004) a relação negativa entre peso e salário foi eliminada para todos os grupos, exceto mulheres brancas. Em Wada e Tekin (2010) as mudanças ocorreram entre homens hispânicos e mulheres negras, cujos coeficientes estimados do peso passaram de negativo para positivo. 
instrumento (IMC do irmão) seja não-correlacionado com $G_{i t}$ e $N G_{i t}$.

Para argumentar que o IMC do irmão é não-correlacionado com $N G_{i t}$, Cawley apóia-se em estudos que encontraram que a correlação entre pesos familiares pode ser atribuída a genes compartilhados, não se devendo a efeitos atribuídos ao ambiente familiar (VOGLER et al., 1995; STUNKARD et al., 1986; SØRENSEN; STUNKARD, 1993). Além disso, provavelmente os irmãos não moram no mesmo domicílio há muitos anos, enfraquecendo qualquer possível efeito do ambiente domiciliar. Cawley argumenta ainda que o IMC do irmão também deve ser não-correlacionado com $G_{i t}$, dizendo que os genes que determinam os salários são diferentes dos que determinam o peso. Como resultado das estimativas, Cawley obteve de modo geral que os coeficientes estimados por VI tiveram mesma direção daqueles estimados por MQO.

O exemplo anterior torna evidente a dificuldade de se encontrar instrumentos válidos. Com efeito, todos os instrumentos para o IMC testados na literatura até hoje já passaram por críticas que colocam em dúvida a hipótese de exogeneidade do instrumento. Kortt e Leigh (2010) produziram um levantamento destes instrumentos citando algumas das limitações. Atella, Pace e Vuri (2008) comentam que a melhor estratégia seria então usar o IMC de irmãos (gêmeos) de mesmo sexo. Na prática, isto nem sempre é possível, no entanto. Em muitas pesquisas - a POF, inclusive - não é possível identificar irmãos que não moram no mesmo domicílio; aqueles que moram provavelmente ainda estudam ou não estão trabalhando, o que torna este instrumento impraticável em muitos casos.

Seguindo a linha de instrumentos da área da família, Morris (2006) adotou o IMC médio do domicílio e a prevalência da obesidade no domicílio como instrumentos do IMC individual. Pode-se argumentar que tais instrumentos são relevantes por capturar hábitos alimentares e de atividade física de pessoas com bagagem genética compartilhada. Para aumentar as chances de exogeneidade dos instrumentos, Morris adicionou um amplo conjunto de variáveis de controle respectivas às características socioeconômicas e da área domiciliar. Os resultados dos coeficientes estimados do IMC passaram a ser positivos e não significativos quando estimados por VI. 
Estratégias semelhantes foram adotadas por Brunello e d'Hombres (2007) e Morris (2007). O primeiro definiu uma regra para utilizar o IMC de um membro biológico familiar (podendo ser pais, filhos ou irmãos) como instrumento. O segundo adotou a prevalência da obesidade no domicílio como instrumento do IMC individual.

Com os avanços recentes na literatura de genética, alguns artigos têm explorado a bagagem individual genética como variação exógena para a obesidade. Norton e Han (2008) e Böckerman et al. (2016) valem-se de single nucleotide polymorphisms (SNP) que mostraram influência direta na predisposição a ser obeso. No entanto, uma ameaça a esta estratégia consiste na possibilidade de existência de pleiotropia - isto é, genes terem mais de uma função - o que poderia implicar que os genes usados afetem o emprego através de outros canais além da obesidade.

Alguns instrumentos singulares também foram aplicados pela literatura internacional. Greve (2008) adotou uma dummy que indica se os pais do entrevistado tiveram prescrição médica de alguma doença genética vinculada à obesidade. Assim como os instrumentos anteriores, este instrumento também aproveita o aspecto genético da obesidade, ao pressupor que os filhos herdam dos pais a predisposição a desenvolver a obesidade. Shimokawa (2008) escolheu uma variável indicativa dos preços dos alimentos como instrumento. O autor defende que os preços dos alimentos devem ser correlacionados com variações não-genéticas do peso e, além disso, supondo que os preços dos alimentos são determinados em ambiente de mercado competitivo, estes devem ser não-correlacionados com o termo de erro dos modelos de salário.

Cabe aqui mencionar que, em parte considerável dos trabalhos que aplicaram variáveis instrumentais para lidar com a endogeneidade do IMC nos modelos de salário, testes de Hausman não rejeitaram a hipótese de que os coeficientes MQO e VI são iguais (por exemplo, Cawley (2004), Morris (2006) e Shimokawa (2008)). Dito de outro modo, nestes casos não foi possível capturar problemas de endogeneidade referentes ao IMC e costuma-se dizer que as estimativas MQO devem ser preferidas. Vale lembrar, no entanto, que isto também pode ser um indicativo de falta de instrumentos adequados, o que deixa 
espaço para novas pesquisas testarem outros instrumentos.

\subsection{Discriminação por peso no trabalho}

O aumento das taxas de obesidade coloca-nos em alerta para um novo tipo de segregação: a discriminação por peso. Atualmente, o número de relatos de discriminação por peso já é semelhante ao de discriminação por cor e gênero (PUHL; ANDREYEVA; BROWNELL, 2008). No entanto, diferenciais de salário não podem ser atribuídos exclusivamente à discriminação. Sendo assim, para finalizar esta revisão bibliográfica, trazemos uma discussão acerca da discriminação por peso e do modo como interpretar os diferentes resultados obtidos entre obesos e não-obesos no mercado de trabalho.

Junto com o aumento da obesidade, nota-se que houve também aumento da discriminação por peso. Com dados longitudinais de uma década, Andreyeva, Puhl e Brownell (2008) traçam a evolução para os EUA. A prevalência de relatos de discriminação por peso entre adultos saltou de 7,3\% em 1995-1996 para 12,2\% em 2004-2006. O estudo investigou também a discriminação por etnia, gênero, idade e raça. No último ano da pesquisa, a taxa de discriminação por peso foi inferior às taxas de discriminação por gênero $(18,7 \%)$ e idade (14\%) mas superior às taxas de discriminação por raça (11\%) e etnia $(4,9 \%)$. Enquanto que a discriminação por raça e etnia mantiveram-se praticamente constantes, a discriminação por peso foi a que mais apresentou crescimento entre todas as categorias, com alta de $66 \%$ no período.

A discriminação por peso atinge diferentes esferas, incluindo educação, trabalho e sistema de saúde. Em enquete feita com professores de ensino médio, $28 \%$ considera que ser obeso é uma das piores coisas que pode acontecer com uma pessoa; $27 \%$ concorda que obesos são mais prováveis a terem problemas na família e 17,5\% concorda que obesos têm menos chances de serem bem-sucedidos no trabalho (FALKNER et al., 1999). Em enquete com enfermeiras, $24 \%$ considera que cuidar de um paciente obeso é repulsivo (BAGLEY et al., 1989). Em enquete com pais de alunos, estudantes obesos recebem em média menos recursos de seus pais para arcar com gastos de estudos, quando comparados com os filhos 
não-obesos. Há ainda evidências de discriminação por peso no ingresso à universidade, em processos de adoção e de aluguel de apartamentos (PUHL; BROWNELL, 2001).

No emprego, as primeiras pesquisas sobre esse tipo de discriminação investigaram o efeito da aparência física no mercado de trabalho. Em entrevista com empregadores, Bobo et al. (2000) perguntam quão importante é a aparência física no momento de preencher uma vaga: $39 \%$ responderam ser importante e 11\% responderam ser de extrema importância. Em linha a este estudo, Hamermesh e Biddle (1994) exploraram o impacto da aparência no salário usando avaliações de aparência física dos entrevistados. Pessoas com aparência abaixo da média obtinham salários menores do que as de aparência mediana. Além disso, verificou-se um prêmio nos salários entre as de melhor aparência física. Portanto, se a aparência física é importante no mercado de trabalho, cogita-se que medidas antropométricas indicativas de obesidade também sejam - esta conjectura é reforçada em Oreffice e Quintana-Domeque (2016), ao constatar que características antropométricas têm papel importante na avaliação de atratividade.

Roehling et al. (2008) realizaram experimentos em que participantes avaliaram qualificações fictícias de candidatos a um emprego, onde o peso do candidato era manipulado. As avaliações incluíram recomendações de contratação ou não, decisão de salário e local de trabalho. Verificou-se como resultado que candidatos em excesso de peso obtiveram resultados piores em todos os quesitos na seleção de vagas.

Em outro estudo experimental, Rooth (2009) simula duas aplicações igualmente qualificadas para a seleção de uma vaga de modo que a única diferença seria a foto apresentada no currículo: uma foto era de um indivíduo de peso normal, e a outra era a mesma pessoa com foto digitalmente modificada para parecer obeso. Encontrou-se que obesos têm no mínimo $20 \%$ menos chances de receber um retorno para entrevista. Além disso, o candidato obeso é chamado com menos frequência principalmente em ocupações que incluem contato direto com o consumidor, tais como vendas e empregos em restaurante.

O cômputo da intensidade da discriminação por peso no mercado de trabalho foi também realizado por outros estudos. Com dados dos EUA de adultos, Roehling e 
Pichler (2007) verificaram que indivíduos em excesso de peso são 12 vezes mais prováveis a reportar discriminação no emprego do que indivíduos de peso normal. Obesos são 37 vezes mais prováveis e indivíduos severamente obesos são 100 vezes mais prováveis a reportar discriminação no emprego. Além disso, a pesquisa verificou que mulheres são 16 vezes mais prováveis do que homens a reportar discriminação por peso no emprego. Isto corrobora com outros trabalhos que encontraram que o efeito estigmatizante da obesidade é ainda maior entre mulheres (SOBAL; STUNKARD, 1989; PERALTA, 2003).

Apesar da alta prevalência de discriminação por peso, não há leis federais que proíbam diretamente esta forma de discriminação. No Brasil, em especial, o $7^{\circ}$ artigo, inciso XXX da Constituição Federal proíbe a diferença de salários por motivo de sexo, idade, cor ou estado civil, sem mencionar, no entanto, peso ou aparência física. Puhl e Heuer (2011) conduziram uma pesquisa on-line com uma amostra de adultos representativa dos EUA com o objetivo de avaliar o apoio público a prováveis medidas legislativas para proibir a discriminação por peso. Os resultados apontam expressiva adesão (65\% dos homens, $81 \%$ das mulheres) para leis que proíbam a discriminação por peso no local de trabalho, especialmente as que proíbem os empregadores de recusar a contratar, demitir ou negar promoção com base no peso corporal.

Considera-se, portanto, que discriminação está entre as possíveis explicações para diferenças salariais. Entretanto, salienta-se que existem muitas dificuldades em se determinar ao certo os motivos de menores salários verificados em alguns grupos de obesos, já que indivíduos obesos podem possuir saúde e produtividade diferentes de indivíduos não-obesos. Nota-se, por exemplo, que pacientes com obesidade mórbida que passam por cirurgia bariátrica para redução de peso reportam melhora significativa na produtividade do trabalho (SOCKALINGAM et al., 2015).

Em síntese, entre as razões para diferenças salariais inclui-se: discriminação por gostos (do empregador ou do consumidor), discriminação estatística e diferenças reais na produtividade. $^{7}$

$\overline{7}$ Caliendo e Lee (2013) descrevem o que modelos teóricos têm a dizer sobre a discriminação estatística. Em especial, Becker (2010) assume que alguns indivíduos têm preferência à discriminação o que, neste 
Entre os trabalhos empíricos que buscaram isolar os canais de influência do peso no salário, destaca-se por exemplo a pesquisa de Atella, Pace e Vuri (2008), que constatou que a relação negativa se mantém, mesmo após controlar por outros fatores - variáveis que sinalizam produtividade, comportamento míope dos agentes e prestação de seguro de saúde por parte dos empregadores. Estas diferenças salariais residuais reforçariam a tese de que há discriminação entre obesos.

Em Dackehag, Gerdtham e Nordin (2014), buscou-se reexaminar esta questão, separando os efeitos da discriminação dos efeitos de perda de produtividade, em decorrência de pior estado de saúde. Controlando por variáveis de saúde individuais, os autores reportam como resultado que a discriminação, e nem tanto diferenças na produtividade, explicam as fontes de penalidades entre obesos no mercado de trabalho.

caso, implicaria que obesos fossem contratados com menor frequência por alguns empregadores. Em outro modelo teórico, Aigner e Cain (1977) assumem que as firmas são avessas ao risco, implicando que a discriminação ocorresse onde há maior incerteza sobre a produtividade dos agentes. 


\section{Base de Dados}

Usamos a base de dados mais recente da Pesquisa de Orçamentos Familiares (POF 2008-2009). A POF é decorrente de um trabalho de 12 meses do IBGE em que foram pesquisados cerca de 60 mil domicílios residentes nas áreas urbanas e rurais de todas as unidades da federação.

A estrutura dos microdados da POF permite-nos incorporar a estrutura amostral complexa de ponderação. A atribuição de pesos nas estimações é realizada designando as variáveis que contêm as informações sobre o desenho amostral, o estrato geográfico e o número sequencial.

Neste trabalho, a POF mostrou-se relevante devido à sua representatividade nacional e principalmente pela disponibilidade das variáveis de saúde, dados antropométricos e de rendimentos do trabalho. A coleta de informações sobre a ocupação e o tipo de emprego possibilita, também, avaliar eventuais efeitos heterogêneos a depender do tipo de atividade exercida pelo indivíduo.

A vantagem de usar a POF mais recente consiste em capturar a realidade atual de excesso de peso no Brasil. Como a prevalência da obesidade vem aumentando com o tempo, avaliar seus efeitos no salário e no emprego requer dados atualizados. Até o momento, a POF contempla os microdados mais recentes das características de antropometria e rendimentos.

Cabe aqui frisar que a POF se preocupou em levar a balança e a fita métrica nas entrevistas domiciliares. Esta é, inclusive, uma fragilidade de alguns estudos internacionais que, diante da ausência de instrumentos de medição, usaram dados auto-reportados de peso corporal e altura. Madden (2013) examinou a diferença entre os dados reportados e os dados medidos encontrando evidências de que a notificação falsa do IMC é sistemática e não-aleatória, o que seria motivo sério de preocupação de inconsistência de estimativas. Ter medido efetivamente os dados antropométricos é mais um ponto favorável da POF.

Selecionamos nossa amostra mantendo os indivíduos entre 20 e 60 anos, excluindo-se 
as gestantes e alguns tipos de ocupações do setor público ${ }^{1}$. A base resultante foi construída através da combinação de características individuais, de emprego e das características domiciliares.

$1 \quad$ Mais especificamente, excluímos os militares (da aeronáutica, exército, marinha, polícia e bombeiros) e os membros superiores e dirigentes do poder público. Juntas, estas ocupações representam $0,8 \%$ da amostra. 


\section{Estratégias Empíricas}

A metodologia está dividida em 3 etapas. A escolha dos métodos aqui empregados deu-se em linha com a recente literatura internacional que busca meios de lidar com a heterogeneidade e a endogeneidade. Acredita-se que, com base nestas estratégias, será possível traçar um panorama amplo de evidências empíricas brasileiras acerca do impacto do excesso de peso no mercado de trabalho.

\section{a. Mínimos Quadrados Ordinários (MQO)}

Nosso modelo de referência será:

$$
\log \text { Salario }_{i}=\delta \operatorname{Index}_{i}+\boldsymbol{x}_{\boldsymbol{i}} \beta+u_{i}
$$

em que logSalario é log do salário-hora proveniente do trabalho principal, em outras palavras, a variável que indica o resultado no mercado de trabalho, $\boldsymbol{x}$ é um vetor de variáveis exógenas e Index é um índice indicativo de obesidade (por exemplo, IMC, peso, etc).

Na tentativa de capturar efeitos heterogêneos do IMC no salário, estimaremos especificações que permitam efeitos não-lineares do IMC.

Nossas estimações estão resumidas em seis categorias:

(i) regressão de logSalario sobre IMC: possibilita observar a associação direta entre as duas variáveis;

(ii) regressão de log Salario sobre IMC e controles: observa a associação entre as duas variáveis controlando por outros fatores que também afetam o salário;

(iii) regressão de logSalario sobre IMC, $\mathrm{IMC}^{2}$ e controles: contempla efeitos nãolineares do IMC no salário - seu efeito marginal permite obter o valor estimado de IMC cujo salário é máximo;

(iv) regressão de log Salario sobre altura, peso e controles: permite identificar o efeito de cada componente do IMC isoladamente; 
(v) regressão de logSalario sobre as dummies subpeso $\left(<18,5 \mathrm{~kg} / \mathrm{m}^{2}\right)$, sobrepeso $\left(25 \leq \mathrm{IMC}<30 \mathrm{~kg} / \mathrm{m}^{2}\right)$, obeso $\left(\geq 30 \mathrm{~kg} / \mathrm{m}^{2}\right)$ e controles: permite diferentes efeitos no salário a depender da faixa de IMC;

(vi) regressão de logSalario sobre as dummies subpeso $\left(<18,5 \mathrm{~kg} / \mathrm{m}^{2}\right)$, sobrepeso $\left(25 \leq \mathrm{IMC}<30 \mathrm{~kg} / \mathrm{m}^{2}\right)$, obesI $\left(30 \leq \mathrm{IMC}<35 \mathrm{~kg} / \mathrm{m}^{2}\right)$, obesII $\left(35 \leq \mathrm{IMC}<40 \mathrm{~kg} / \mathrm{m}^{2}\right)$, obesIII ( $\left.>40 \mathrm{~kg} / \mathrm{m}^{2}\right)$ e controles: esta estratégia seria um refinamento da estimação anterior ao dividir o IMC em faixas menores.

Com o objetivo de considerar eventuais efeitos heterogêneos da ocupação, os resultados serão reportados por grupos. A investigação por grupo será dividida por gênero (homens e mulheres) e tipo de trabalho (white collar e blue collar).

No que concerne ao tipo de trabalho, existe uma classificação internacional que divide as profissões. Trabalhadores blue collar correspondem aos indivíduos que executam serviços manuais (cuja habilidade varia por ocupação), o que inclui trabalhadores de serviços gerais, mecânica, serviços elétricos e estruturais. Trabalhadores white collar performam serviços em escritório, geralmente trabalhos que requerem alta habilidade e treinamento, o que inclui economistas, médicos e engenheiros. Através do arquivo de relação de códigos da Classificação Brasileira de Ocupações disponibilizado pela POF, associamos as ocupações declaradas na pesquisa à classificação internacional.

Mais especificamente, chamamos de white collar as ocupações de dirigentes, gerentes, profissionais (das exatas, biológicas, sociais, etc), técnicos de nível médio, escriturários e trabalhadores de atendimento ao público. Chamamos de blue collar as ocupações de produtores e trabalhadores na exploração agrícola, trabalhadores industriais e construção civil. Trabalhadores de comércio e serviços foram divididos entre as duas categorias, a depender da ocupação. 


\section{b. Regressão Quantílica}

É reconhecido que a estimação de médias condicionais continua valiosa, no entanto, a estimação de medianas condicionais, e de modo mais geral, de quantis condicionais, é cada vez mais popular na pesquisa empírica (WOOLDRIDGE, 2010). Isto é especialmente válido nos casos em que a variável explicativa tem diferentes efeitos ao longo de diferentes segmentos da variável de interesse. A estimação por quantil permite-nos reconhecer estes diferentes efeitos.

A teoria de regressão quantílica é atribuída a Koenker e Jr (1978). Os trabalhos de Chamberlain (1994) e Buchinsky (1994) são considerados aplicações pioneiras de regressão quantílica na estimativa de mudanças ao longo da distribuição de salário. Mais recentemente, Atella, Pace e Vuri (2008) trouxeram esta abordagem para os estudos de obesidade e mercado de trabalho.

Inúmeras vantagens são atribuídas ao método de regressão quantílica. Em especial, o método fornece flexibilidade ao modelar dados com distribuições condicionais heterogêneas. Além disso, em muitos casos, o método mostra-se mais robusto a valores extremos - em particular, a regressão na mediana costuma ser mais robusta a outliers do que a regressão por MQO (HUBER, 2011). Por fim, a regressão quantílica provê uma rica caracterização dos dados, podendo mostrar diferentes efeitos das variáveis explicativas de acordo com o espectro da variável dependente.

No nosso caso, a regressão quantílica pode ser descrita pela seguinte equação:

$$
\log \text { Salario }_{i}=\delta \text { Index }_{i}+\boldsymbol{x}_{\boldsymbol{i}} \boldsymbol{\beta}_{\boldsymbol{q}}+u_{i}
$$

onde $\beta_{\boldsymbol{q}}$ é o vetor de parâmetros desconhecidos associado ao q-ésimo quantil, de modo que diferentes escolhas de $q$ estimam diferentes coeficientes.

Vale aqui fazer uma distinção importante entre os métodos. MQO minimiza $\sum_{i=1}^{n} u_{i}^{2}$, a soma dos quadrados do erro do modelo. A regressão na mediana, também chamada de regressão de desvios absolutos, minimiza $\sum_{i=1}^{n}\left|u_{i}\right|$. A regressão quantílica, por sua vez, minimiza $\sum_{i=1}^{n} q\left|u_{i}\right|+\sum_{i=1}^{n}(1-q)\left|u_{i}\right|$, soma que dá penalidades assimétricas: $q\left|u_{i}\right|$ para a 
subpredição e $(1-q)\left|u_{i}\right|$ para a sobrepredição.

O estimador do q-ésimo quantil, $\hat{\beta}_{\boldsymbol{q}}$, é obtido minimizando a função objetivo sobre $\beta_{q}:$

$$
\begin{array}{r}
Q\left(\beta_{\boldsymbol{q}}\right)=\sum_{i: \log \text { Salario } i_{i} \geq \boldsymbol{x}_{\boldsymbol{i}} \boldsymbol{\beta}}^{n} q \mid \log \text { Salario }_{i}-\boldsymbol{x}_{\boldsymbol{i}} \boldsymbol{\beta}_{\boldsymbol{q}} \mid+ \\
\sum_{i: \log \text { Salario }_{i}<\boldsymbol{x}_{\boldsymbol{i}} \boldsymbol{\beta}}^{n}(1-q) \mid \log \text { Salario }_{i}-\boldsymbol{x}_{\boldsymbol{i}} \boldsymbol{\beta}_{\boldsymbol{q}} \mid
\end{array}
$$

onde $0<q<1$. Usualmente, o quantil condicional padrão é especificado como sendo linear da forma $Q_{q}\left(\log\right.$ Salario $\left._{i} \mid \boldsymbol{x}_{\boldsymbol{i}}\right)=\boldsymbol{x}_{\boldsymbol{i}} \boldsymbol{\beta}_{\boldsymbol{q}}$. Para o j-ésimo regressor, o efeito marginal é o

coeficiente para o q-ésimo quantil de modo que $\frac{\partial Q_{q}\left(\log \operatorname{Salario}_{i} \mid \boldsymbol{x}\right)}{\partial \boldsymbol{x}_{\boldsymbol{j}}}=\beta_{q j}$. Logo, o parâmetro $\beta_{q j}$ da regressão quantílica consiste na mudança percentual no quantil $q$ do salário, oriunda de uma mudança de uma unidade na variável independente $x_{j}$. Pontanto, diferentemente da regressão por MQO, a interpretação dos resultados de regressão quantílica necessita especificar qual quantil da variável dependente estamos analisando.

Dois tipos de significância são importantes no contexto de regressão quantílica: (i) observar se os coeficientes da regressão quantílica são estatisticamente diferentes de zero; (ii) observar se os coeficientes da regressão quantílica são estatisticamente diferentes dos coeficientes de MQO, revelando assim diferentes efeitos ao longo da distribuição do salário. Este segundo tipo significância é apresentado nos gráficos das estimações por quantil.

\section{c. Endogeneidade e Variáveis Instrumentais (VI)}

Sabemos que se $u$ é não-correlacionado com Index e $\boldsymbol{x}$, então MQO irá produzir estimativas consistentes do impacto de Index no resultado do mercado de trabalho. Sendo Index endógeno na equação de salário, a consistência das estimativas obtidas via MQO não é garantida. Neste caso aplicaremos o método de Variáveis Instrumentais. Supomos 
que Index, a medida de obesidade, tem a seguinte forma reduzida:

$$
\operatorname{Index}_{i}=\boldsymbol{x} \beta+z \boldsymbol{\alpha}+\varepsilon_{i}
$$

onde $\boldsymbol{z}$ é um vetor de variáveis exógenas correlacionadas com Index, $\alpha$ um vetor de coeficientes e $\varepsilon$ o termo de erro não-correlacionado com $u$.

Aqui o desafio é encontrar instrumentos apropriados para Index. Em outras palavras, procuramos variáveis- $z$ que sejam correlacionadas com Index e ortogonais ao erro $(\operatorname{cov}(z, u)=0)$.

A revisão bibliográfica dos instrumentos abordou as inúmeras dificuldades de se encontrar variáveis instrumentais adequadas para a obesidade na equação do salário. Estimase que 40 a $70 \%$ da variabilidade do IMC entre indivíduos é devida a fatores genéticos (LOCKE et al., 2015). Na tentativa de contemplar o caráter genético da obesidade, medidas baseadas na área familiar são recorrentemente usadas como instrumentos. Em linha com a literatura estrangeira, usaremos as medidas médias de obesidade dos indivíduos adultos vivendo no domicílio. Essa estratégia foi adotada, por exemplo, por Brunello e d'Hombres (2007), Cawley (2004), Morris (2006) e Morris (2007). 



\section{Resultados}

A tabela 1 contempla as estatísticas descritivas das principais variáveis incluídas nos modelos. Entre as medidas representativas de obesidade estão: peso, altura, IMC e suas respectivas dummies que representam as categorias de IMC. Entre as variáveis de controle, destacamos as variáveis de educação, idade e dummy de estado civil e uma dummy que identifica se o indivíduo tem plano de saúde ${ }^{1}$.

Tabela 1 - Estatísticas das principais variáveis incluídas nos modelos

\begin{tabular}{rrrrrrrrrr}
\hline & \multicolumn{4}{c}{ Homens } & \multicolumn{4}{c}{ Mulheres } \\
& white collar & \multicolumn{2}{c}{ blue collar } & \multicolumn{2}{c}{ white collar } & \multicolumn{2}{c}{ blue collar } \\
& Média & DP & Média & DP & Média & DP & Média & DP \\
\hline log salario-hora & 1,880 & 0,009 & 1,257 & 0,005 & 1,593 & 0,009 & 0,908 & 0,007 \\
IMC & 26,100 & 0,039 & 25,139 & 0,023 & 24,87 & 0,041 & 25,636 & 0,041 \\
subpeso & 0,013 & 0,001 & 0,016 & 0,001 & 0,036 & 0,002 & 0,031 & 0,001 \\
sobrepeso & 0,412 & 0,005 & 0,358 & 0,003 & 0,277 & 0,004 & 0,318 & 0,004 \\
obeso & 0,159 & 0,003 & 0,106 & 0,002 & 0,133 & 0,003 & 0,168 & 0,003 \\
altura & 1,721 & 0,001 & 1,700 & 0,000 & 1,603 & 0,001 & 1,584 & 0,001 \\
peso & 77,382 & 0,130 & 72,746 & 0,076 & 63,84 & 0,109 & 64,326 & 0,107 \\
idade & 36,869 & 0,103 & 37,366 & 0,064 & 35,68 & 0,091 & 38,079 & 0,087 \\
anos de estudo & 10,021 & 0,039 & 6,259 & 0,024 & 10,8 & 0,034 & 6,986 & 0,032 \\
casado & 0,350 & 0,004 & 0,144 & 0,002 & 0,385 & 0,004 & 0,160 & 0,003 \\
plano de saúde & 0,617 & 0,005 & 0,653 & 0,003 & 0,506 & 0,004 & 0,551 & 0,004 \\
Observações & 11.267 & 28.595 & 13.060 & 14.274 \\
\hline
\end{tabular}

A tabela 2 contém informações descritivas das ocupações agregadas. Na primeira coluna apresentamos a classificação white e blue collar; na segunda, terceira e quarta colunas apresentamos o percentual de trabalhadores respectivamente entre toda a amostra, obesos e pessoas com IMC normal.

Conforme detalhado no capítulo anterior, separaremos as estimações em seis modelos. O modelo 1 traz a regressão simples do log salário-hora sobre o IMC. Nos modelos 2 a 5, adicionamos as variáveis de controle. No modelo 3 incorporamos o termo quadrático do IMC. No modelo 4 estimamos os efeitos de peso e altura, ceteris paribus. Nos modelos 5 e

1 Em todos os modelos, as seguintes variáveis também foram incluídas como controles: dummies de cor/raça, região, ruralidade, condição de ocupação e dummies de número de crianças vivendo no domicílio. Adicionamos também uma dummy que indica se o indivíduo teve necessidade de algum medicamento no último mês, mas não adquiriu por falta de recursos. 
Tabela 2 - Frequência de Ocupações

\begin{tabular}{rcccc}
\hline & W/B & $\%$ & \% entre Obesos & \% entre IMC Normal \\
\hline Dirigentes ou gerentes & $\mathrm{W}$ & $3,98 \%$ & $5,29 \%$ & $3,25 \%$ \\
Profissionais (exatas, biológicas, etc) & $\mathrm{W}$ & $5,94 \%$ & $5,96 \%$ & $6,14 \%$ \\
Técnicos de nível médio & $\mathrm{W}$ & $6,90 \%$ & $8,02 \%$ & $6,41 \%$ \\
Escriturários & $\mathrm{W}$ & $5,92 \%$ & $5,11 \%$ & $6,46 \%$ \\
Comércio e atendimento ao público & $\mathrm{W} / \mathrm{B}$ & $13,21 \%$ & $14,22 \%$ & $12,96 \%$ \\
Serviços & $\mathrm{W} / \mathrm{B}$ & $21,54 \%$ & $24,70 \%$ & $20,60 \%$ \\
Trabalhadores Agrícolas & $\mathrm{B}$ & $18,56 \%$ & $14,52 \%$ & $20,68 \%$ \\
Indústria extrativa e da const. civil & $\mathrm{B}$ & $7,35 \%$ & $4,78 \%$ & $8,05 \%$ \\
Trabalhadores industriais & $\mathrm{B}$ & $16,60 \%$ & $17,39 \%$ & $15,44 \%$ \\
\hline
\end{tabular}

$\mathrm{W}$ : white, B: blue collar.

6 separamos a medida de obesidade em faixas de IMC.

\subsection{MQO}

As tabelas 3 e 4 contém os resultados por MQO para homens white e blue collar. A primeira especificação indica um efeito positivo de 3,7\% para homens white collar e de 3,9\% para homens blue collar no salário, oriundo do aumento de uma unidade de IMC. Este efeito cai respectivamente para 1,5\% e 1,9\%, na segunda especificação, ao adicionar as variáveis de controle. A terceira especificação permite dizer que o salário atinge seu valor máximo ao IMC a $34,7 \mathrm{~kg} / \mathrm{m}^{2}$ para white collar e $41,3 \mathrm{~kg} / \mathrm{m}^{2}$ para blue collar, indicando que em média homens com valores altos de IMC recebem maiores salários. Isto é confirmado através do efeito da variável peso da quarta especificação e nos coeficientes das dummies de obesidade nas quinta e sexta especificações. Verifica-se que o impacto positivo do IMC no salário entre homens persiste mesmo entre indivíduos excessivamente obesos.

Contata-se, portanto, efeitos positivos da obesidade no salário e que estes efeitos são ainda mais expressivos entre homens blue collar. Este resultado positivo encontrado para homens corrobora com os resultados de Loh (1993), Greve (2008) e Majumder (2013). O fato de que o efeito do IMC no salário entre homens white collar é inferior ao de blue collar - resultado semelhante ao encontrado por Caliendo e Gehrsitz (2014) - pode ser considerado evidência de diferenças no perfil de trabalhadores homens entre ocupações. Pode haver "portly banker effect", ou seja, um maior IMC para homens pode ser sinalizador 
de força/poder, beneficiando homens em sobrepeso em algumas profissões. Devemos lembrar também que homens com boa condição física e alta massa muscular também estão incluídos na categoria blue collar, podendo superestimar o coeficiente encontrado para a obesidade.

Entre mulheres, os resultados caminham no sentido oposto. As tabelas 5 e 6 contém os resultados por MQO para mulheres white e blue collar. Na primeira especificação encontramos que o aumento de uma unidade de IMC está associado a uma queda de 0,3\% e 0,2\% no salário para white e blue collar, mas estes efeitos não são estatisticamente significativos. Encontramos efeitos significativos negativos entre mulheres white collar na segunda especificação, ao adicionar os controles, e nas quinta e sexta especificações. A terceira especificação revela que o salário atinge seu valor máximo ao IMC de $22,3 \mathrm{~kg} / \mathrm{m}^{2}$ para mulheres white collar e de $28,8 \mathrm{~kg} / \mathrm{m}^{2}$ para blue collar.

Os resultados negativos da obesidade no salário verificados entre mulheres está de acordo com a grande maioria da literatura existente - podemos destacar, por exemplo, os trabalhos de Cawley (2004), Johansson et al. (2009) e Larose et al. (2016). Além disso, acredita-se que a aparência física seja mais importante entre ocupações white collar. Isto pode ajudar a entender por que o IMC cujo salário é máximo para mulheres white collar reside a um nível substancialmente inferior a $25 \mathrm{~kg} / \mathrm{m}^{2}$ (limiar para o excesso de peso). Caliendo e Gehrsitz (2014) interpreta este resultado como sendo evidência de prêmio à beleza entre mulheres. 
Tabela 3 - Impacto do IMC no salário para homens white collar - MQO, variável dependente é log salário-hora

\begin{tabular}{|c|c|c|c|c|c|c|}
\hline & Modelo 1 & Modelo 2 & Modelo 3 & Modelo 4 & Modelo 5 & Modelo 6 \\
\hline IMC & $\begin{array}{c}0,037 \\
(16,38) \\
* * *\end{array}$ & $\begin{array}{c}0,015 \\
(7,85) \\
* * *\end{array}$ & $\begin{array}{c}0,071 \\
(4,56) \\
* * *\end{array}$ & & & \\
\hline $\mathrm{IMC}^{2}$ & & & $\begin{array}{c}-0,001 \\
(-3,64) \\
* * *\end{array}$ & & & \\
\hline subpeso & & & & & $\begin{array}{c}-0,178 \\
(-2,93) \\
* * *\end{array}$ & $\begin{array}{c}-0,178 \\
(-2,93) \\
* * *\end{array}$ \\
\hline sobrepeso & & & & & $\begin{array}{c}0,092 \\
(5,50) \\
* * *\end{array}$ & $\begin{array}{c}0,092 \\
(5,50) \\
* * *\end{array}$ \\
\hline obeso & & & & & $\begin{array}{c}0,144 \\
(5,89) \\
* * *\end{array}$ & \\
\hline obesI & & & & & & $\begin{array}{c}0,151 \\
(5,71) \\
* * *\end{array}$ \\
\hline obesII & & & & & & $\begin{array}{c}0,145 \\
(2,62) \\
* * *\end{array}$ \\
\hline obesIII & & & & & & $\begin{array}{l}-0,004 \\
(-0,03)\end{array}$ \\
\hline altura & & & & $\begin{array}{c}0,770 \\
(6,10) \\
* * *\end{array}$ & & \\
\hline peso & & & & $\begin{array}{c}0,005 \\
(7,00) \\
* * *\end{array}$ & & \\
\hline $\begin{array}{r}\text { Controles } \\
\text { Obs. }\end{array}$ & Não & \multicolumn{5}{|c|}{11107} \\
\hline
\end{tabular}

Estatísticas t robustas entre parênteses. ${ }^{*}$ significativo a $10 \%,{ }^{* *} 5 \%, * * * 1 \%$. 
Tabela 4 - Impacto do IMC no salário para homens blue collar - MQO, variável dependente é log salário-hora

\begin{tabular}{|c|c|c|c|c|c|c|}
\hline & Modelo 1 & Modelo 2 & Modelo 3 & Modelo 4 & Modelo 5 & Modelo 6 \\
\hline IMC & $\begin{array}{c}0,039 \\
(32,16) \\
* * *\end{array}$ & $\begin{array}{c}0,019 \\
(16,83) \\
* * *\end{array}$ & $\begin{array}{l}0,054 \\
(5,89) \\
* * *\end{array}$ & & & \\
\hline $\mathrm{IMC}^{2}$ & & & $\begin{array}{c}-0,001 \\
(-3,86) \\
* * *\end{array}$ & & & \\
\hline subpeso & & & & & $\begin{array}{c}-0,116 \\
(-3,33) \\
* * *\end{array}$ & $\begin{array}{c}-0,116 \\
(-3,33) \\
* * *\end{array}$ \\
\hline sobrepeso & & & & & $\begin{array}{c}0,112 \\
(12,15) \\
* * *\end{array}$ & $\begin{array}{c}0,112 \\
(12,15) \\
* * *\end{array}$ \\
\hline obeso & & & & & $\begin{array}{c}0,169 \\
(11,30) \\
* * *\end{array}$ & \\
\hline obesI & & & & & & $\begin{array}{c}0,155 \\
(9,52) \\
* * *\end{array}$ \\
\hline obesII & & & & & & $\begin{array}{c}0,226 \\
(6,36) \\
* * *\end{array}$ \\
\hline obesIII & & & & & & $\begin{array}{c}0,299 \\
(4,15) \\
* * *\end{array}$ \\
\hline altura & & & & $\begin{array}{c}0,363 \\
(5,17) \\
* * *\end{array}$ & & \\
\hline peso & & & & $\begin{array}{c}0,007 \\
(17,17) \\
* * *\end{array}$ & & \\
\hline $\begin{array}{r}\text { Controles } \\
\text { Obs. }\end{array}$ & Não & Sim & $\operatorname{Sim}_{27}$ & 8 & Sim & Sim \\
\hline
\end{tabular}

Estatísticas t robustas entre parênteses. ${ }^{*}$ significativo a $10 \%,{ }^{* *} 5 \%,{ }^{* * *} 1 \%$. 
Tabela 5 - Impacto do IMC no salário para mulheres white collar - MQO, variável dependente é log salário-hora

\begin{tabular}{|c|c|c|c|c|c|c|}
\hline & Modelo 1 & Modelo 2 & Modelo 3 & Modelo 4 & Modelo 5 & Modelo 6 \\
\hline IMC & $\begin{array}{l}-0,003 \\
(-1,60)\end{array}$ & $\begin{array}{c}-0,006 \\
(-3,30) \\
* * *\end{array}$ & $\begin{array}{c}0,023 \\
(2,00) \\
* *\end{array}$ & & & \\
\hline $\mathrm{IMC}^{2}$ & & & $\begin{array}{c}-0,001 \\
(-2,50) \\
* *\end{array}$ & & & \\
\hline subpeso & & & & & $\begin{array}{c}-0,082 \\
(-2,10) \\
* *\end{array}$ & $\begin{array}{c}-0,082 \\
(-2,10) \\
* *\end{array}$ \\
\hline sobrepeso & & & & & $\begin{array}{l}-0,027 \\
(-1,56)\end{array}$ & $\begin{array}{l}-0,027 \\
(-1,56)\end{array}$ \\
\hline obeso & & & & & $\begin{array}{c}-0,091 \\
(-3,75) \\
* * *\end{array}$ & \\
\hline obesI & & & & & & $\begin{array}{c}-0,086 \\
(-3,08) \\
* * *\end{array}$ \\
\hline obesII & & & & & & $\begin{array}{c}-0,088 \\
(-1,83) \\
*\end{array}$ \\
\hline obesIII & & & & & & $\begin{array}{c}-0,161 \\
(-1,88) \\
*\end{array}$ \\
\hline altura & & & & $\begin{array}{c}1,112 \\
(9,36) \\
* * *\end{array}$ & & \\
\hline peso & & & & $\begin{array}{c}-0,002 \\
(-2,29) \\
* *\end{array}$ & & \\
\hline $\begin{array}{r}\text { Controles } \\
\text { Obs. }\end{array}$ & Não & \multicolumn{4}{|c|}{12897} & Sim \\
\hline
\end{tabular}

Estatísticas t robustas entre parênteses. * significativo a $10 \%,{ }^{* *} 5 \%,{ }^{* * *} 1 \%$. 
Tabela 6 - Impacto do IMC no salário para mulheres blue collar - MQO, variável dependente é log salário-hora

\begin{tabular}{|c|c|c|c|c|c|c|}
\hline & Modelo 1 & Modelo 2 & Modelo 3 & Modelo 4 & Modelo 5 & Modelo 6 \\
\hline IMC & $\begin{array}{l}0,002 \\
(1,59)\end{array}$ & $\begin{array}{l}0,001 \\
(0,36)\end{array}$ & $\begin{array}{c}0,029 \\
(3,19) \\
* * *\end{array}$ & & & \\
\hline $\mathrm{IMC}^{2}$ & & & $\begin{array}{c}-0,001 \\
(-3,16) \\
* * *\end{array}$ & & & \\
\hline subpeso & & & & & $\begin{array}{c}-0,096 \\
(-2,59) \\
* *\end{array}$ & $\begin{array}{c}-0,096 \\
(-2,59) \\
* *\end{array}$ \\
\hline sobrepeso & & & & & $\begin{array}{l}-0,008 \\
(-0,56)\end{array}$ & $\begin{array}{l}-0,008 \\
(-0,56)\end{array}$ \\
\hline obeso & & & & & $\begin{array}{c}-0,016 \\
(-0,87) \\
* * *\end{array}$ & \\
\hline obesI & & & & & & $\begin{array}{l}-0,012 \\
(-0,59)\end{array}$ \\
\hline obesII & & & & & & $\begin{array}{l}-0,006 \\
(-0,18)\end{array}$ \\
\hline obesIII & & & & & & $\begin{array}{l}-0,088 \\
(-1,37)\end{array}$ \\
\hline altura & & & & $\begin{array}{c}0,801 \\
(8,15) \\
* * *\end{array}$ & & \\
\hline peso & & & & $\begin{array}{l}0,001 \\
(1,23)\end{array}$ & & \\
\hline $\begin{array}{r}\text { Controles } \\
\text { Obs. }\end{array}$ & Não & Sim & Sim 27 & ${ }_{98}^{\text {Sim }}$ & Sim & Sim \\
\hline
\end{tabular}

Estatísticas t robustas entre parênteses. * significativo a $10 \%, * * 5 \%, * * * 1 \%$. 


\subsection{Regressão Quantílica}

Com a finalidade de explorar a heterogeneidade do efeito no salário, faremos a estimação por quantil buscando entender como se dá o efeito da obesidade ao longo da distribuição do salário.

Como é comum em estimações via regressão quantílica, iniciamos apresentando, na Figura 1, o gráfico da distribuição dos indivíduos da amostra segundo a variável dependente, o log do salário-hora. Além disso, antes da execução da regressão quantílica, realizamos testes de heteroscedasticidade. As estatísticas de Breusch-Pagan mostraram-se significativamente diferentes de zero indicando evidências de heteroscedasticidade ${ }^{2}$, o que, em certa medida, ajuda a fortalecer o uso do método da regressão por quantil.

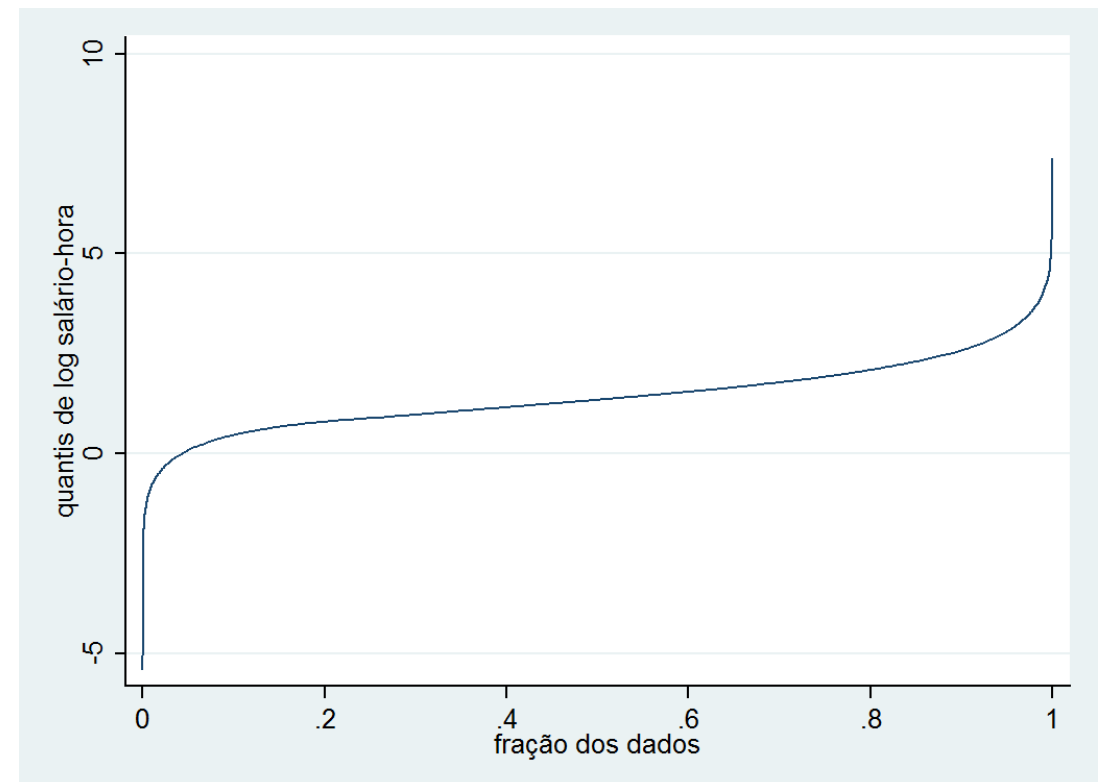

Figura 1 - Fração dos dados ao longo dos quantis da variável dependente

Na estimação quantílica optamos por reportar os resultados para a especificação que envolve as dummies subpeso, sobrepeso e obeso, juntamente com os gráficos dos coeficientes estimados por quantil. Como a estimação por quantil já é uma estratégia que leva em conta a heterogeneidade do salário, optamos agora por colocar a dummy white collar como controle da regressão ao invés de fazer a estimação separadamente para cada

$2 \quad$ Mais especificadamente, as estatísticas dos testes de Breusch-Pagan resultaram em $\chi^{2}(24)=1043,98$ para homens e $\chi^{2}(24)=951,01$ para mulheres. 
grupo.

As tabelas 7 e 8 contém os resultados estimados por quantil. Entre homens, constatase que o efeito da obesidade no salário é positivo e crescente conforme aumenta o quantil de salário. Em particular, o coeficiente estimado indica um efeito de 16,9\% da obesidade entre homens do $75^{\circ}$-quantil.

Entre mulheres, nota-se resultados significativos da obesidade apenas no grupo de quantil inferior. Ceteris paribus, nota-se um impacto negativo, de 4,1\%, da obesidade no salário. Efeito semelhante foi encontrado em Atella (2008).

Os gráficos presentes nas figuras 2 e 3 trazem uma forma diferente de observar os resultados, permitindo-nos comparar os coeficientes estimados via MQO e regressão quantílica, bem como seus intervalos de confiança para as dummies de peso. Como de costume, nosso foco reside na variável de obesidade. As curvas estimadas evidenciam diferenças substanciais entre os dois métodos de estimação, em especial, para a dummy obeso masculina, onde o coeficiente de MQO localiza-se predominantemente fora do intervalo de confiança da regressão quantílica, e para a dummy obeso feminina, onde evidencia-se diferenças principalmente nos grupos inferiores de quantil. Deste modo, vê-se que o método por quantil contribui para revelar outras dimensões do impacto da obesidade no salário, que poderiam ser negligenciadas usando apenas a análise convencional. 
Tabela 7 - Impacto do IMC no salário para homens - Regressão quantílica, variável dependente é log salário-hora

\begin{tabular}{cccc}
\hline & $\mathrm{q}(25 \mathrm{th})$ & $\mathrm{q}(50 \mathrm{th})$ & $\mathrm{q}(75 \mathrm{th})$ \\
\hline subpeso & $-0,122$ & $-0,159$ & $-0,073$ \\
& $(-3,65)$ & $(-4,91)$ & $(-1,79)$ \\
& $* * *$ & $* * *$ & $*$ \\
sobrepeso & 0,089 & 0,088 & 0,103 \\
& $(9,79)$ & $(10,02)$ & $(9,22)$ \\
& $* * *$ & $* * *$ & $* * *$ \\
obeso & 0,124 & 0,143 & 0,169 \\
& $(9,26)$ & $(11,06)$ & $(10,30)$ \\
& $* * *$ & $* * *$ & $* * *$
\end{tabular}

Controles Sim Sim Sim

Obs. $\quad 39105$

Estatísticas t entre parênteses. ${ }^{*}$ significativo a $10 \%,{ }^{* *} 5 \%, * * * 1 \%$.

Tabela 8 - Impacto do IMC no salário para mulheres - Regressão quantílica, variável dependende é log salário-hora

\begin{tabular}{cccc}
\hline & $\mathrm{q}(25 \mathrm{th})$ & $\mathrm{q}(50 \mathrm{th})$ & $\mathrm{q}(75 \mathrm{th})$ \\
\hline subpeso & $-0,055$ & $-0,081$ & $-0,059$ \\
& $(-1,71)$ & $(-2,89)$ & $(-1,73)$ \\
& $*$ & $* *$ & $*$ \\
sobrepeso & 0,009 & 0,004 & $-0,027$ \\
& $(0,66)$ & $(0,35)$ & $(-1,96)$ \\
& & & $*$ \\
obeso & $-0,041$ & $-0,011$ & $-0,009$ \\
& $(-2,42)$ & $(-0,72)$ & $(-0,51)$ \\
& $* *$ & &
\end{tabular}

Controles Sim Sim Sim

Obs. $\quad 26887$

Estatísticas t entre parênteses. ${ }^{*}$ significativo a $10 \%,{ }^{*} * 5 \%, * * * 1 \%$. 

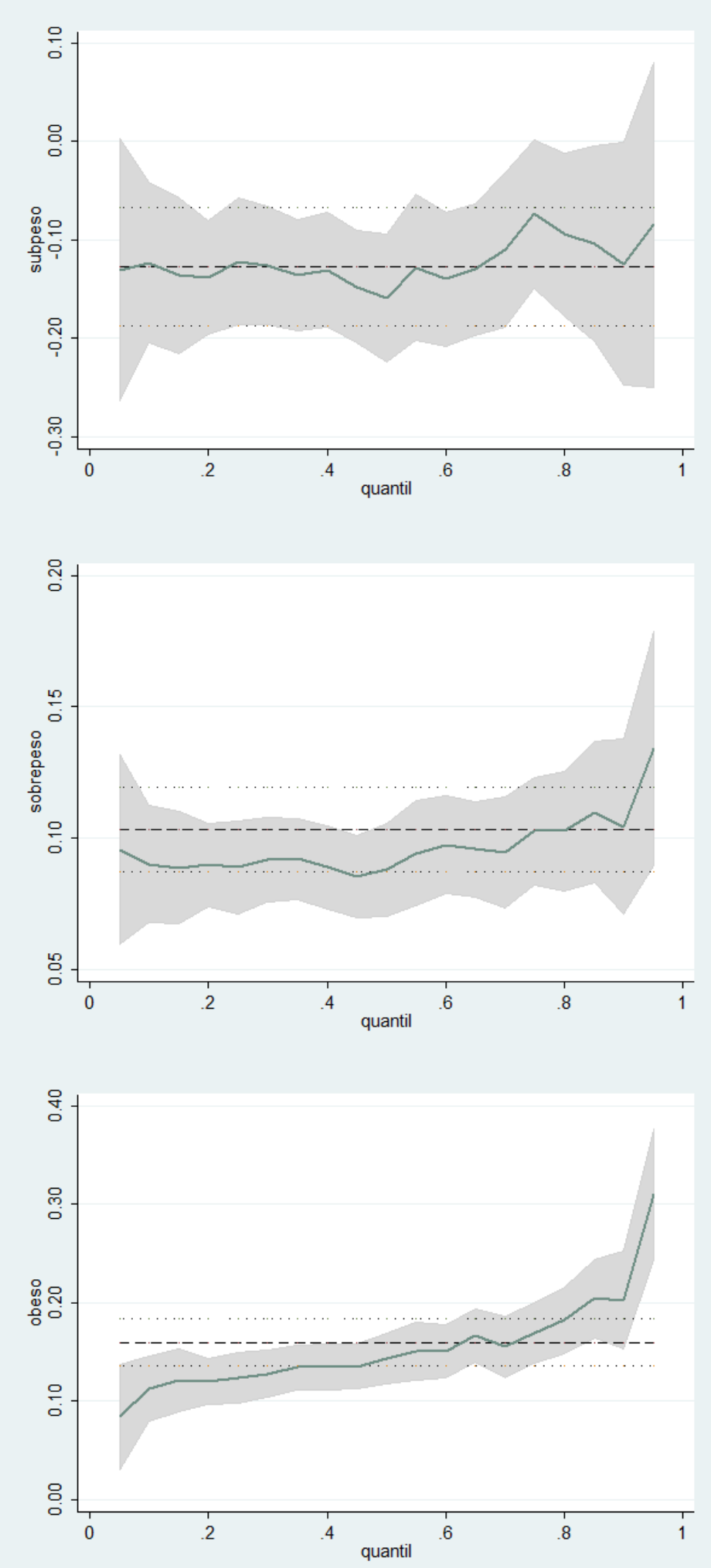

Figura 2 - Coeficientes da Regressão Quantílica e Intervalos de Confiança para homens 

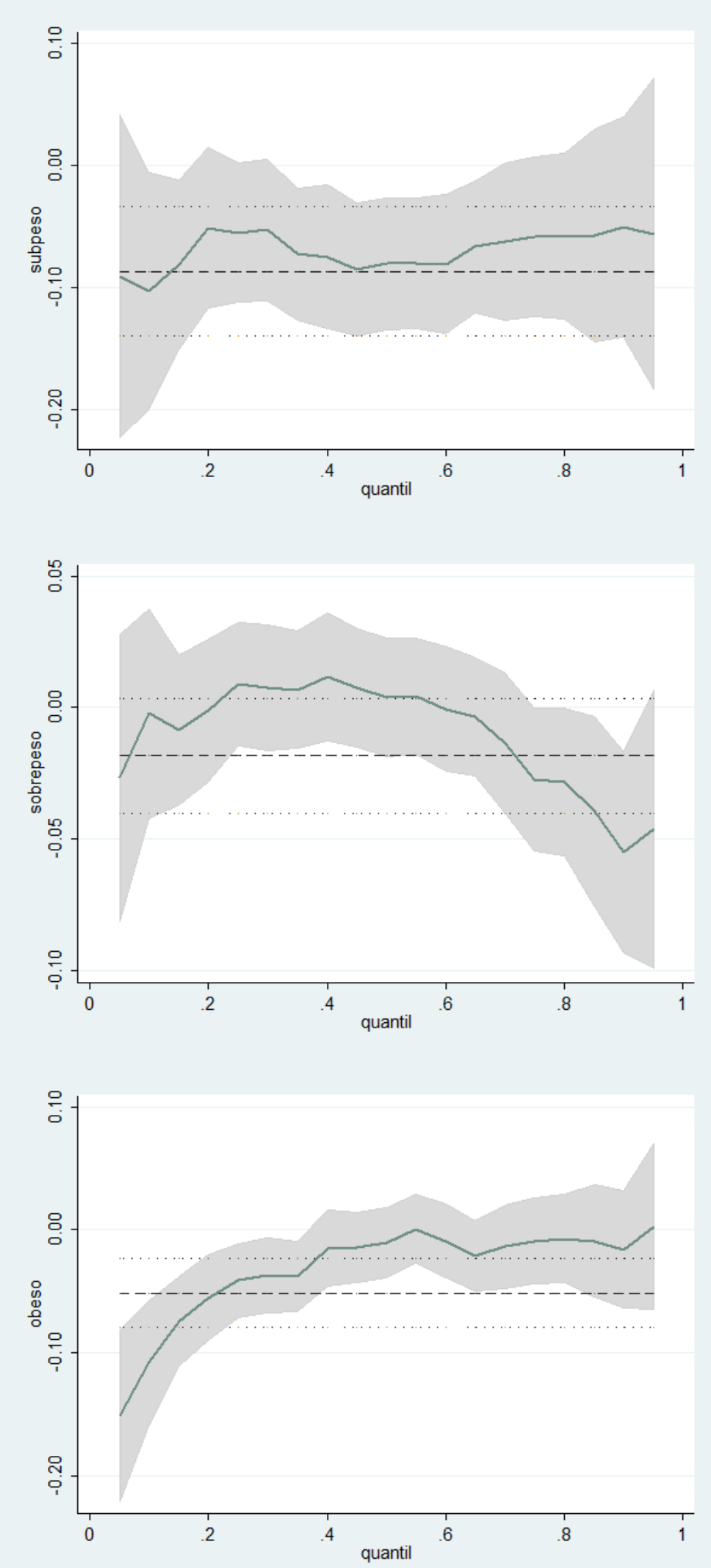

Figura 3 - Coeficientes da Regressão Quantílica e Intervalos de Confiança para mulheres 


\subsection{Variáveis Instrumentais}

Com o objetivo de lidar com a endogeneidade da obesidade nos modelos de salário, aplicaremos o método de variáveis instrumentais. Medidas de obesidade familiares ou medidas inerentes ao domicílio são amplamente empregadas como instrumento para a obesidade individual (por exemplo, Brunello e d'Hombres (2007), Cawley (2004), Morris (2006) e Morris (2007)). Esta estratégia baseia-se em dois pilares fundamentais: (i) aproveita o fato de que o nível de obesidade do indivíduo é altamente correlacionado com a obesidade de um familiar próximo - sustentando a relevância do instrumento - e (ii) pressupõe que esta correlação se dá geneticamente, através da predisposição genética a desenvolver a obesidade - sustentando a exogeneidade do instrumento.

Discutimos, ao longo do texto, algumas das limitações destes instrumentos empregados na literatura. Para estimar com microdados brasileiros temos a restrição adicional de que não conseguimos identificar familiares que moram em domicílios separados e temos pouca informação sobre a ligação genética entre indivíduos o que inviabiliza aplicar alguns instrumentos. Sendo assim, amparando-se nos pressupostos da literatura existente, usaremos as medidas médias de obesidade dos indivíduos adultos vivendo no domicílio como instrumento - estratégia semelhante à adotada por Morris (2007), em artigo publicado no Journal of Health Economics.

As tabelas 9 a 12 contém os resultados por Variáveis Instrumentais. Reportamos os resultados por gênero e tipo de trabalho. Conforme destacado anteriormente, usamos como instrumentos para a obesidade individual as médias de variáveis domiciliares, de modo que os instrumentos variam, portanto, a depender do modelo considerado. Em cada tabela reportamos também os resultados de testes de significância dos instrumentos nas regressões de primeiro estágio; todas as estatísticas obtidas apontam para a significância conjunta, sustentando a hipótese de relevância dos instrumentos utilizados. Testes de Hausman foram reportados ao final e, em geral, indicam diferenças significativas entre os modelos MQO e VI, o que reforça o diagnóstico de presença de endogeneidade na medida de obesidade. 
Entre homens white collar, a primeira especificação por VI traz um efeito positivo, mas agora de 2,3\% do IMC no salário na primeira especificação, e de 0,8\% na especificação com controles. A terceira especificação permite dizer que o salário atinge seu valor máximo ao IMC a $30,6 \mathrm{~kg} / \mathrm{m}^{2}$. Nas quarta e quinta especificações encontramos efeitos significativos das medidas de obesidade, similares aos efeitos por MQO. Entre homens blue collar os resultados estimados por VI caminham na mesma direção dos obtidos por MQO, embora menores em magnitude ${ }^{3}$.

Os resultados entre mulheres por VI são mistos. Entre mulheres white collar, encontramos efeitos negativos da obesidade no salário nos modelos 2 e 5, mas estatisticamente não significativos; enquanto isso, o modelo 3 estima que o salário atinja máximo a $25,9 \mathrm{~kg} / \mathrm{m}^{2}$. Já em mulheres blue collar encontramos efeitos positivos (embora pouco expressivos) do IMC no salário nos modelos 1 e 2. No modelo 3 nota-se que o salário atinge máximo a $31,7 \mathrm{~kg} / \mathrm{m}^{2}$. No modelo 5 não encontramos resultados significativos nas variáveis de obesidade.

De modo geral, podemos dizer que os resultados por VI concordam com resultados obtidos por MQO - padrão similar ao encontrado por Morris (2006), o que ajuda a reforçar nossas conclusões. A diferença de resultados obtida entre os grupos white e blue collar por gênero sustenta o argumento inicial da presença de heterogeneidade entre tipos de ocupações. Considerar esta diversidade ajuda a entender, por exemplo, por que a penalidade da obesidade no salário é frequente entre mulheres white collar, cuja aparência física pode ser mais importante à vaga do que nas ocupações blue collar.

3 Mais especificadamente, nota-se um efeito positivo de 1,6\% do IMC no salário na especificação com controles e estima-se que o salário atinja máximo a $35,5 \mathrm{~kg} / \mathrm{m}^{2}$ entre homens blue collar. 
Tabela 9 - Impacto do IMC no salário para homens white collar - VI, variável dependente é log salário-hora

\begin{tabular}{|c|c|c|c|c|c|}
\hline & Modelo 1 & Modelo 2 & Modelo 3 & Modelo 4 & Modelo 5 \\
\hline IMC & $\begin{array}{c}0,023 \\
(7,33) \\
* * *\end{array}$ & $\begin{array}{c}0,008 \\
(3,15) \\
* * *\end{array}$ & $\begin{array}{c}0,098 \\
(3,54) \\
* * *\end{array}$ & & \\
\hline $\mathrm{IMC}^{2}$ & & & $\begin{array}{c}-0,001 \\
(-3,21) \\
* * *\end{array}$ & & \\
\hline subpeso & & & & & $\begin{array}{l}-0,077 \\
(-0,42)\end{array}$ \\
\hline sobrepeso & & & & & $\begin{array}{l}0,158 \\
(3,23) \\
* * *\end{array}$ \\
\hline obeso & & & & & $\begin{array}{c}0,072 \\
(1,67) \\
*\end{array}$ \\
\hline altura & & & & $\begin{array}{c}0,76 \\
(5,55) \\
* * *\end{array}$ & \\
\hline peso & & & & $\begin{array}{l}0,005 \\
(5,35) \\
* * *\end{array}$ & \\
\hline Controles & Não & Sim & Sim & Sim & Sim \\
\hline $\begin{array}{r}\text { Instrumento }(\mathrm{s}) \\
\text { Est. } \mathrm{F} \\
{[p-\text { valor }]}\end{array}$ & $\begin{array}{c}\text { IMC } \\
8363,5 \\
{[0,0000]}\end{array}$ & $\begin{array}{c}\mathrm{IMC} \\
7870,5 \\
{[0,0000]}\end{array}$ & $\begin{array}{c}\text { IMC, } \text { IMC }^{2} \\
5081,7 \\
{[0,0000]} \\
4242 \\
{[0,0000]}\end{array}$ & $\begin{array}{c}\text { peso } \\
9594,2 \\
{[0,0000]}\end{array}$ & $\begin{array}{c}\text { sub, sobre, obeso } \\
48,6 \\
{[0,0000]} \\
680,8 \\
{[0,0000]} \\
974,2 \\
{[0,0000]}\end{array}$ \\
\hline $\begin{array}{r}\text { T. Hausman } \\
{[p-\text { valor }]} \\
\text { Obs. }\end{array}$ & $\begin{array}{c}48,51 \\
{[0,0000]}\end{array}$ & $\begin{array}{c}9,24 \\
{[0,0024]}\end{array}$ & $\begin{array}{c}4,91 \\
{[0,0074]} \\
11107\end{array}$ & $\begin{array}{c}0,03 \\
{[0,8558]}\end{array}$ & $\begin{array}{c}2,49 \\
{[0,0584]}\end{array}$ \\
\hline
\end{tabular}

Estatísticas t robustas entre parênteses. ${ }^{*}$ significativo a $10 \%,{ }^{*} * 5 \%, * * * 1 \%$. 
Tabela 10 - Impacto do IMC no salário para homens blue collar - VI, variável dependente é log salário-hora

\begin{tabular}{|c|c|c|c|c|c|}
\hline & Modelo 1 & Modelo 2 & Modelo 3 & Modelo 4 & Modelo 5 \\
\hline IMC & $\begin{array}{c}0,038 \\
(21,19) \\
* * *\end{array}$ & $\begin{array}{c}0,016 \\
(9,53) \\
* * *\end{array}$ & $\begin{array}{l}0,066 \\
(3,80) \\
* * *\end{array}$ & & \\
\hline $\mathrm{IMC}^{2}$ & & & $\begin{array}{c}-0,001 \\
(-2,88) \\
* * *\end{array}$ & & \\
\hline subpeso & & & & & $\begin{array}{l}-0,119 \\
(-1,47)\end{array}$ \\
\hline sobrepeso & & & & & $\begin{array}{l}0,101 \\
(3,69) \\
* * *\end{array}$ \\
\hline obeso & & & & & $\begin{array}{l}0,147 \\
(4,97) \\
* * *\end{array}$ \\
\hline altura & & & & $\begin{array}{c}0,312 \\
(3,97) \\
* * *\end{array}$ & \\
\hline peso & & & & $\begin{array}{c}0,007 \\
(12,93) \\
* * *\end{array}$ & \\
\hline Controles & Não & Sim & Sim & Sim & Sim \\
\hline $\begin{array}{r}\text { Instrumento }(\mathrm{s}) \\
\text { Est. } \mathrm{F} \\
{[p-\text { valor }]}\end{array}$ & $\begin{array}{c}\text { IMC } \\
16021 \\
{[0,0000]}\end{array}$ & $\begin{array}{c}\text { IMC } \\
14054 \\
{[0,0000]}\end{array}$ & $\begin{array}{c}{\text { IMC }, \mathrm{IMC}^{2}}+11040 \\
{[0,0000]} \\
9362,2 \\
{[0,0000]}\end{array}$ & $\begin{array}{c}\text { peso } \\
16516,6 \\
{[0,0000]}\end{array}$ & $\begin{array}{c}\text { sub, sobre, obeso } \\
289,59 \\
{[0,0000]} \\
1872 \\
{[0,0000]} \\
1431,33 \\
{[0,0000]}\end{array}$ \\
\hline $\begin{array}{r}\text { T. de Hausman } \\
{[p-\text { valor }]} \\
\text { Obs. }\end{array}$ & $\begin{array}{c}3,13 \\
{[0,0768]}\end{array}$ & $\begin{array}{c}7,02 \\
{[0,0081]}\end{array}$ & $\begin{array}{c}3,84 \\
{[0,0216]} \\
27998\end{array}$ & $\begin{array}{c}2,60 \\
{[0,1069]}\end{array}$ & $\begin{array}{c}0,58 \\
{[0,6304]}\end{array}$ \\
\hline
\end{tabular}

Estatísticas t robustas entre parênteses. ${ }^{*}$ significativo a $10 \%, * * 5 \%, * * * 1 \%$. 
Tabela 11 - Impacto do IMC no salário para mulheres white collar - VI, variável dependente é log salário-hora

\begin{tabular}{|c|c|c|c|c|c|}
\hline & Modelo 1 & Modelo 2 & Modelo 3 & Modelo 4 & Modelo 5 \\
\hline IMC & $\begin{array}{l}0,003 \\
(1,17)\end{array}$ & $\begin{array}{l}-0,003 \\
(-1,40)\end{array}$ & $\begin{array}{c}0,043 \\
(2,14) \\
* * *\end{array}$ & & \\
\hline $\mathrm{IMC}^{2}$ & & & $\begin{array}{c}-0,001 \\
(-2,30) \\
* *\end{array}$ & & \\
\hline subpeso & & & & & $\begin{array}{l}-0,056 \\
(-0,52)\end{array}$ \\
\hline sobrepeso & & & & & $\begin{array}{l}-0,043 \\
(-0,96)\end{array}$ \\
\hline obeso & & & & & $\begin{array}{l}-0,039 \\
(-0,97)\end{array}$ \\
\hline altura & & & & $\begin{array}{c}0,922 \\
(7,37) \\
* * *\end{array}$ & \\
\hline peso & & & & $\begin{array}{l}0,002 \\
(1,62)\end{array}$ & \\
\hline Controles & Não & Sim & Sim & Sim & Sim \\
\hline $\begin{array}{r}\text { Instrumento }(\mathrm{s}) \\
\text { Est. } \mathrm{F} \\
{[p-\text { valor }]}\end{array}$ & $\begin{array}{c}\text { IMC } \\
12141,9 \\
{[0,0000]}\end{array}$ & $\begin{array}{c}\text { IMC } \\
10544 \\
{[0,0000]}\end{array}$ & $\begin{array}{c}\text { IMC, } \text { IMC }^{2} \\
6631,43 \\
{[0,0000]} \\
4889,22 \\
{[0,0000]}\end{array}$ & $\begin{array}{c}\text { peso } \\
7308,7 \\
{[0,0000]}\end{array}$ & $\begin{array}{c}\text { sub, sobre, obeso } \\
352,14 \\
{[0,0000]} \\
832,45 \\
{[0,0000]} \\
1256,09 \\
{[0,0000]}\end{array}$ \\
\hline $\begin{array}{r}\text { T. de Hausman } \\
{[p-\text { valor }]} \\
\text { Obs. }\end{array}$ & $\begin{array}{c}15,10 \\
{[0,0001]}\end{array}$ & $\begin{array}{c}3,44 \\
{[0,0081]}\end{array}$ & $\begin{array}{c}2,39 \\
{[0,0914]} \\
12897\end{array}$ & $\begin{array}{c}22,7 \\
{[0,0000]}\end{array}$ & $\begin{array}{c}0,89 \\
{[0,4461]}\end{array}$ \\
\hline
\end{tabular}

Estatísticas t robustas entre parênteses. ${ }^{*}$ significativo a $10 \%,{ }^{*} * 5 \%, * * * 1 \%$. 
Tabela 12 - Impacto do IMC no salário para mulheres blue collar - VI, variável dependente é log salário-hora

\begin{tabular}{|c|c|c|c|c|c|}
\hline & Modelo 1 & Modelo 2 & Modelo 3 & Modelo 4 & Modelo 5 \\
\hline IMC & $\begin{array}{l}0,012 \\
(6,75) \\
* * *\end{array}$ & $\begin{array}{c}0,005 \\
(2,87) \\
* * *\end{array}$ & $\begin{array}{l}0,043 \\
(3,45) \\
* * *\end{array}$ & & \\
\hline $\mathrm{IMC}^{2}$ & & & $\begin{array}{c}-0,001 \\
(-3,14) \\
* * *\end{array}$ & & \\
\hline subpeso & & & & & $\begin{array}{l}0,005 \\
(0,06)\end{array}$ \\
\hline sobrepeso & & & & & $\begin{array}{l}0,036 \\
(1,03)\end{array}$ \\
\hline obeso & & & & & $\begin{array}{l}0,058 \\
(2,00) \\
* *\end{array}$ \\
\hline altura & & & & $\begin{array}{l}0,620 \\
(6,02) \\
* * *\end{array}$ & \\
\hline peso & & & & $\begin{array}{l}0,004 \\
(5,00)\end{array}$ & \\
\hline Controles & Não & Sim & Sim & Sim & Sim \\
\hline $\begin{array}{r}\text { Instrumento }(\mathrm{s}) \\
\text { Est. } \mathrm{F} \\
{[p-\text { valor }]}\end{array}$ & $\begin{array}{c}\text { IMC } \\
18442,5 \\
{[0,0000]}\end{array}$ & $\begin{array}{c}\text { IMC } \\
17021 \\
{[0,0000]}\end{array}$ & $\begin{array}{c}{\text { IMC }, \mathrm{IMC}^{2}} \\
9940,55 \\
{[0,0000]} \\
7192,4 \\
{[0,0000]}\end{array}$ & $\begin{array}{c}\text { peso } \\
11061,5 \\
{[0,0000]}\end{array}$ & $\begin{array}{c}\text { sub, sobre, obeso } \\
391,9 \\
{[0,0000]} \\
1288,6 \\
{[0,0000]} \\
2266,2 \\
{[0,0000]}\end{array}$ \\
\hline $\begin{array}{r}\text { T. de Hausman } \\
{[p-\text { valor }]} \\
\text { Obs. }\end{array}$ & $\begin{array}{c}81,36 \\
{[0,0000]}\end{array}$ & $\begin{array}{c}18,05 \\
{[0,0000]}\end{array}$ & $\begin{array}{c}9,24 \\
{[0,0001]} \\
13990\end{array}$ & $\begin{array}{c}36,8 \\
{[0,0000]}\end{array}$ & $\begin{array}{c}4,86 \\
{[0,0022]}\end{array}$ \\
\hline
\end{tabular}

Estatísticas t robustas entre parênteses. * significativo a $10 \%,{ }^{*} * 5 \%, * * * 1 \%$. 


\section{Considerações finais}

Existe uma vasta literatura de evidências acerca das consequências econômicas da obesidade. Neste trabalho estimamos o impacto da obesidade no mercado de trabalho usando microdados brasileiros. A pesquisa contribui à literatura em três dimensões fundamentais: (i) incorporamos efeitos heterêgeneos e não-lineares da obesidade; (ii) consideramos efeitos heterogêneos ao longo da distribuição do salário e (iii) lidamos com a endogeneidade da medida de obesidade na equação de salário.

Destaca-se, entre os resultados estimados, que a obesidade está associada à uma penalidade de 3,9\% (VI) a 9,1\% (MQO) no salário entre mulheres white collar mesmo após controlar pelas explicativas. Na estimação por quantil nota-se que as mulheres do quantil inferior são as mais penalizadas pela obesidade. Enquanto isso, estima-se que homens obesos white collar recebem em média de 7,2\% (VI) a 14,4\% (MQO) a mais que os não-obesos. Nota-se também que o efeito positivo da obesidade é maior entre homens do quantil superior.

Entre os efeitos heterogêneos diagnosticados pela pesquisa podemos ressaltar os diferentes resultados obtidos por sexo e tipo de ocupação.

Mesmo considerando a produtividade, parte da literatura atribui o efeito negativo da obesidade no trabalho como resultado de discriminação por peso principalmente entre mulheres. Constata-se que mulheres são mais propensas do que os homens a relatar a discriminação por peso no emprego (ROEHLING; PICHLER, 2007) ${ }^{1}$. Sendo assim, suspeita-se que a obesidade é mais estigmatizante entre mulheres, o que ajuda a explicar os coeficientes aqui encontrados.

No que concerne a heterogeneidade do trabalho, verificamos que o excesso de peso parece ser menos penalizador no salário entre ocupações blue collar do que nas ocupações white collar em ambos os sexos. Isto pode ser evidência de que a aparência

1 Também pode haver um comportamento auto-discriminador entre alguns indivíduos em excesso de peso, o que afetaria na negociação de salários na relação trabalhador-empregado. Em estudo experimental, Branas-Garza, Proestakis et al. (2014) constatam que mulheres obesas solicitaram recompensas monetárias significativamente menores, em comparação com as não-obesas. 
física é mais relevante entre ocupações white collar. Além disso, nas ocupações blue collar devem incluir muitos indivíduos com IMC elevado devido à alta massa muscular, o que não necessariamente caracterizaria obesidade.

Apesar de seu amplo uso, o IMC é cada vez mais visto como uma medida imprecisa para a obesidade. Sabe-se que alguns indivíduos com IMC normal apresentam padrão metabólico de indivíduos em sobrepeso-obesidade (CONUS; RABASA-LHORET; PERONNET, 2007). Outros, com alto IMC, apresentam padrão metabólico saudável (PRIMEAU et al., 2011). Atribui-se, como limitação ao índice, o fato de que o IMC não leva em conta diferenças na composição corporal (MCCARTHY et al., 2006). Por não distinguir o que é gordura corporal e o que são músculos e ossos, o IMC sobrestima, por exemplo, a gordura presente entre aqueles com elevada massa muscular. Outros índices como o percentual de massa gorda e a circunferência da cintura são medidas mais precisas da gordura corporal e são apontados como melhores preditores de mortalidade do que o IMC (STAIANO et al., 2012; TRAYHURN; BEATTIE, 2001). Burkhauser e Cawley (2008) e Johansson et al. (2009), por exemplo, encontraram que também entre homens o aumento da massa gorda está negativamente associado ao emprego. Conclui-se, portanto que definir obesidade usando o IMC resulta em erros de classificação no status de peso corporal e que outros índices são importantes no diagnóstico de obesidade e na avaliação de seu impacto no mercado de trabalho.

A divulgação de dados brasileiros de outros índices antropométricos assim como informações mais detalhadas de produtividade, estilo de vida e tipo de trabalho podem contribuir para determinar com mais clareza os canais em que o excesso de peso afeta o mercado de trabalho.

Este trabalho não Vale reforçar que grande parte das estimativas causais das consequências da obesidade é baseada no uso do peso de membros da família como instrumento para o peso individual. No entanto, existem preocupações quanto à validade destes instrumentos, pois estes podem afetar os resultados do emprego através de outras vias, como fatores comuns ao ambiente domiciliar (KORTT; LEIGH, 2010). 
Evidentemente, há espaço para pesquisas futuras testarem novos instrumentos. Na medicina persiste o interesse de explorar a bagagem genética individual para isolar quais os genes que influenciam as variáveis de saúde e quais afetam os resultados no mercado de trabalho. É recente o uso destas informações como instrumento para a obesidade (HINKE et al., 2015; BÖCKERMAN et al., 2016). Acredita-se, portanto, que avanços nas pesquisas genéticas poderão ajudar a identificar com mais rigor os genes determinantes à predisposição da obesidade, permitindo assim a aplicação de novos instrumentos.

Explorar variações exógenas oriundas de experimentos aleatórios ou naturais também é uma possibilidade para pesquisas futuras. Ensaios randomizados de perda de peso podem examinar o efeito da perda de peso em variáveis do mercado de trabalho. Através de randomized controlled trials entre obesos, Augurzky et al. (2012) e Reichert (2015) reportam significativa melhora na produtividade e nas perspectivas de emprego entre mulheres que passaram por redução de peso.

Por fim, acreditamos que a continuidade desta investigação tem inúmeras implicações em políticas públicas. Se há discriminação no salário em decorrência do peso, policy makers podem considerar incluir obesidade entre as leis anti-discriminação (PUHL; HEUER, 2011). Ou ainda, se o excesso de peso afeta a saúde e os resultados no mercado de trabalho, isto implica que programas de prevenção e combate à obesidade deveriam levar isto em conta na análise custo-benefício dos programas (BÖCKERMAN et al., 2016). A relevância destas questões deixa, portanto, espaço para novas evidências. 



\section{Referências}

AIGNER, D. J.; CAIN, G. G. Statistical theories of discrimination in labor markets. Industrial and Labor relations review, JSTOR, p. 175-187, 1977. 32

ANDREYEVA, T.; PUHL, R. M.; BROWNELL, K. D. Changes in perceived weight discrimination among americans, 1995-1996 through 2004-2006. Obesity, Wiley Online Library, v. 16, n. 5, p. 1129-1134, 2008. 29

ATELLA, V.; PACE, N.; VURI, D. Are employers discriminating with respect to weight?: European evidence using quantile regression. Economics 85 Human Biology, Elsevier, v. 6, n. 3 , p. $305-329,2008.24,27,32,37$

AUGURZKY, B. et al. Does money burn fat? Evidence from a randomized experiment. Evidence from a Randomized Experiment (September 1, 2012). Ruhr Economic Paper, n. $368,2012.61$

AVERETT, S. Obesity and labor market outcomes. IZA, 2014. 16

AVERETT, S.; KORENMAN, S. The economic reality of the beauty myth. Journal of Human Resources, v. 31, p. 304-330, 1996. 15, 25, 26

AVERETT, S.; KORENMAN, S. Black-white differences in social and economic consequences of obesity. International journal of obesity, v. 23, n. 2, p. 166-173, 1999. 15

BAGLEY, C. et al. Attitudes of nurses toward obesity and obese patients. Perceptual and Motor skills, Ammons Scientific, v. 68, n. 3, p. 954-954, 1989. 29

BAHIA, L. et al. The costs of overweight and obesity-related diseases in the Brazilian public health system: cross-sectional study. BMC public health, BioMed Central Ltd, v. 12, n. 1 , p. $440,2012.11$

BECKER, G. S. The economics of discrimination. [S.l.]: University of Chicago press, 2010. 31

BOBO, L. et al. Multi-city study of urban inequality, 1992-1994. Inter-University Consortium for Political and Social Research, Ann Arbor, MI, 2000. 30

BÖCKERMAN, P. et al. The Effect of Weight on Labor Market Outcomes: an Application of Genetic Instrumental Variables. [S.1.], 2016. 28, 61

BRANAS-GARZA, P.; PROESTAKIS, A. et al. Self-discrimination: A field experiment on obesity. [S.l.], 2014. 59

BRUNELlO, G.; D'HOMBRES, B. Does body weight affect wages?: Evidence from Europe. Economics \& Human Biology, Elsevier, v. 5, n. 1, p. 1-19, 2007. 16, 28, 39, 53

BUCHINSKY, M. Changes in the us wage structure 1963-1987: Application of quantile regression. Econometrica: Journal of the Econometric Society, JSTOR, p. 405-458, 1994. 37

BURKHAUSER, R. V.; CAWLEY, J. Beyond BMI: the value of more accurate measures of fatness and obesity in social science research. Journal of Health Economics, Elsevier, v. 27, n. 2 , p. $519-529,2008.18,19,60$ 
CALIENDO, M.; GEHRSITZ, M. Obesity and the labor market: A fresh look at the weight penalty. [S.l.], 2014. 19, 22, 23, 42, 43

CALIENDO, M.; LEE, W.-S. Fat chance! Obesity and the transition from unemployment to employment. Economics \& Human Biology, Elsevier, v. 11, n. 2, p. 121-133, 2013. 11, 31

CAWLEY, J. An instrumental variables approach to measuring the effect of body weight on employment disability. Health Services Research, Health Research \& Educational Trust, v. 35 , n. 5 Pt 2, p. $1159,2000.15$

CAWLEY, J. The impact of obesity on wages. Journal of Human Resources, University of Wisconsin Press, v. 39, n. 2, p. 451-474, 2004. 15, 17, 18, 25, 26, 28, 39, 43, 53

CAWLEY, J. An economy of scales: A selective review of obesity's economic causes, consequences, and solutions. Journal of health economics, Elsevier, v. 43, p. 244-268, 2015. 11

CAWLEY, J. H.; GRABKA, M. M.; LILLARD, D. R. A comparison of the relationship between obesity and earnings in the US and Germany. Schmollers Jahrbuch, Berlin: Duncker\&Humblot, v. 125, n. 1, p. 119-129, 2005. 12, 16

CHAMBERLAIN, G. Quantile regression, censoring, and the structure of wages. In: Advances in Econometrics: Sixth World Congress. [S.l.: s.n.], 1994. v. 2, p. 171-209. 37

CONLEY, D.; GLAUBER, R. Gender, body mass, and socioeconomic status: new evidence from the PSID. Advances in health economics and health services research, v. 17, p. $253-275,2007.25$

CONUS, F.; RABASA-LHORET, R.; PERONNET, F. Characteristics of metabolically obese normal-weight (monw) subjects. Applied physiology, nutrition, and metabolism, NRC Research Press, v. 32, n. 1, p. 4-12, 2007. 60

DACKEHAG, M.; GERDTHAM, U.-G.; NORDIN, M. Productivity or discrimination? An economic analysis of excess-weight penalty in the swedish labor market. The European Journal of Health Economics, Springer, p. 1-13, 2014. 16, 32

FALKNER, N. H. et al. Mistreatment due to weight: prevalence and sources of perceived mistreatment in women and men. Obesity Research, Wiley Online Library, v. 7, n. 6, p. 572-576, 1999. 29

GARCIA, J.; QUINTANA-DOMEQUE, C. Obesity, employment, and wages in europe. Advances in health economics and health services research, v. 17, p. 187-217, 2007. 17, 18, 19

GORTMAKER, S. L. et al. Social and economic consequences of overweight in adolescence and young adulthood. New England journal of medicine, Mass Medical Soc, v. 329, n. 14, p. $1008-1012$, 1993. 15, 25

GREGORY, C. A.; RUHM, C. J. Where does the wage penalty bite? In: Economic aspects of obesity. [S.l.]: University of Chicago Press, 2011. p. 315-347. 22, 23 
GREVE, J. Obesity and labor market outcomes: New Danish evidence. [S.l.]: Aarhus School of Business, 2007. 12

GREVE, J. Obesity and labor market outcomes in denmark. Economics 6 H Human Biology, Elsevier, v. 6, n. 3, p. 350-362, 2008. 16, 18, 21, 28, 42

HAMERMESH, D. S.; BIDDLE, J. E. Beauty and the labor market. The American Economic Review, JSTOR, p. 1174-1194, 1994. 19, 30

HILDEBRAND, V.; KERM, P. V. Body size and wages in Europe a semi-parametric analysis. Social and Economic Dimensions of an Aging Population Research Papers, McMaster University, v. 269, 2010. 17, 21, 22, 23

HINKE, S. von et al. Genetic markers as instrumental variables. Journal of health economics, Elsevier, 2015. 61

HUBER, P. J. Robust statistics. [S.1.]: Springer, 2011. 37

JOHANSSON, E. et al. Obesity and labour market success in finland: The difference between having a high bmi and being fat. Economics 85 Human Biology, Elsevier, v. 7, n. 1 , p. $36-45,2009.16,17,43,60$

KOENKER, R.; JR, G. B. Regression quantiles. Econometrica: Journal of the Econometric Society, JSTOR, p. 33-50, 1978. 37

KORTT, M.; LEIGH, A. Does size matter in Australia? Economic Record, Wiley Online Library, v. 86, n. 272, p. 71-83, 2010. 27, 60

KOTCHEN, T. A. Obesity-related hypertension: epidemiology, pathophysiology, and clinical management. American journal of hypertension, Oxford University Press, v. 23, n. 11, p. $1170-1178,2010.11$

LAROSE, S. L. et al. Does obesity influence labour market outcomes among working-age adults? Evidence from Canadian longitudinal data. Economics \& Human Biology, Elsevier, v. 20 , p. 26-41, 2016. 25,43

LOCKE, A. E. et al. Genetic studies of body mass index yield new insights for obesity biology. Nature, Nature Publishing Group, v. 518, n. 7538, p. 197-206, 2015. 39

LOH, E. The economic effect of physical appearance. Social Science Quarterly, v. 74, p. 420-37, 1993. 15, 42

MADDEN, D. D. P. Self-reported and measured BMI in ireland: should we adjust the obesity thresholds? University College Dublin. School of Economics, 2013. 33

MAJUMDER, M. A. Does obesity matter for wages? Evidence from the united states. Economic Papers: A journal of applied economics and policy, Wiley Online Library, v. 32, n. 2, p. 200-217, 2013. 15,42

MCCARTHY, H. et al. Body fat reference curves for children. International journal of obesity, Nature Publishing Group, v. 30, n. 4, p. 598-602, 2006. 60 
MONTEIRO, C. A.; CONDE, W. L.; POPKIN, B. M. Is obesity replacing or adding to undernutrition? Evidence from different social classes in brazil. Public health nutrition, Cambridge Univ Press, v. 5, n. 1A, p. 105-112, 2002. 11

MORRIS, S. Body mass index and occupational attainment. Journal of health economics, Elsevier, v. 25, n. 2, p. 347-364, 2006. 13, 16, 27, 28, 39, 53, 54

MORRIS, S. The impact of obesity on employment. Labour Economics, Elsevier, v. 14, n. 3 , p. 413-433, 2007. $17,28,39,53$

NCD. Trends in adult body-mass index in 200 countries from 1975 to 2014: a pooled analysis of 1698 population-based measurement studies with $19 \cdot 2$ million participants. The Lancet, Elsevier, v. 387, n. 10026, p. 1377-1396, 2016. 11

NORTON, E. C.; HAN, E. Genetic information, obesity, and labor market outcomes. Health Economics, Wiley Online Library, v. 17, n. 9, p. 1089-1104, 2008. 28

OREFFICE, S.; QUINTANA-DOMEQUE, C. Beauty, body size and wages: Evidence from a unique data set. Economics \& Human Biology, Elsevier, v. 22, p. 24-34, 2016. 30

ORGANIZATION, W. H. et al. Obesity and overweight. Fact sheet no. 311; 2014. Geneva: World Health Organization, 2014.

PAGAN, J. A.; DAVILA, A. Obesity, occupational attainment, and earnings. Social Science Quarterly, JSTOR, p. 756-770, 1997. 15, 20

PERALTA, R. L. Thinking sociologically about sources of obesity in the united states. Gender Issues, Springer, v. 21, n. 3, p. 5-16, 2003. 31

PRIMEAU, V. et al. Characterizing the profile of obese patients who are metabolically healthy. International journal of obesity, Nature Publishing Group, v. 35, n. 7, p. 971-981, 2011. 60

PUHL, R.; BROWNELL, K. D. Bias, discrimination, and obesity. Obesity research, Wiley Online Library, v. 9, n. 12, p. 788-805, 2001. 30

PUHL, R. M.; ANDREYEVA, T.; BROWNELL, K. D. Perceptions of weight discrimination: prevalence and comparison to race and gender discrimination in america. International journal of obesity, Nature Publishing Group, v. 32, n. 6, p. 992-1000, 2008. 29

PUHL, R. M.; HEUER, C. A. Public opinion about laws to prohibit weight discrimination in the united states. Obesity, Wiley Online Library, v. 19, n. 1, p. 74-82, 2011. 31, 61

REGISTER, C. A.; WILLIAMS, D. R. Wage effects of obesity among young workers. [S.l.]: Social Science Quarterly, 1990. 130-141 p. 11, 15, 24

REICHERT, A. R. Obesity, weight loss, and employment prospects: Evidence from a randomized trial. Journal of Human Resources, University of Wisconsin Press, v. 50, n. 3, p. $759-810,2015.61$

ROEHLING et al. The effects of weight bias on job-related outcomes: a meta-analysis of experimental studies. Academy of Management Annual Meeting, Anahiem, CA, 2008. 30 
ROEHLING, M. V.; PICHLER, S. The relationship between body weight and perceived weight-related employment discrimination: The role of sex and race. Journal of Vocational Behavior, Elsevier, v. 71, n. 2, p. 300-318, 2007. 31, 59

ROOTH, D.-O. Obesity, attractiveness, and differential treatment in hiring a field experiment. Journal of human resources, University of Wisconsin Press, v. 44, n. 3, p. 710-735, 2009. 30

SARGENT, J. D.; BLANCHFLOWER, D. G. Obesity and stature in adolescence and earnings in young adulthood: analysis of a british birth cohort. Archives of Pediatrics 86 Adolescent Medicine, American Medical Association, v. 148, n. 7, p. 681-687, 1994. 16, 25

SHIMOKAWA, S. The labour market impact of body weight in China: a semiparametric analysis. Applied Economics, Taylor \& Francis, v. 40, n. 8, p. 949-968, 2008. 22, 28

SOBAL, J.; STUNKARD, A. J. Socioeconomic status and obesity: a review of the literature. Psychological bulletin, American Psychological Association, v. 105, n. 2, p. 260, 1989. 31

SOCKALINGAM, S. et al. Employment outcomes one year after bariatric surgery: the role of patient and psychosocial factors. Obesity surgery, Springer, v. 25, n. 3, p. 514-522, 2015. 31

SØRENSEN, T.; STUNKARD, A. J. Does obesity run in families because of genes? Acta Psychiatrica Scandinavica, Wiley Online Library, v. 87, n. S370, p. 67-72, 1993. 27

STAIANO, A. et al. Body mass index versus waist circumference as predictors of mortality in canadian adults. International journal of obesity, Nature Publishing Group, v. 36, n. 11, p. $1450-1454,2012.60$

STUNKARD, A. J. et al. An adoption study of human obesity. New England Journal of Medicine, Mass Medical Soc, v. 314, n. 4, p. 193-198, 1986. 27

TEIXEIRA, A. D.; DIAZ, M. D. M. Obesidade e o sucesso no mercado de trabalho utilizando a POF 2008-2009. Revista Gestão ES Políticas Públicas, v. 1, n. 2, 2012. 12

TRAYHURN, P.; BEATTIE, J. H. Physiological role of adipose tissue: white adipose tissue as an endocrine and secretory organ. Proceedings of the Nutrition Society, Cambridge Univ Press, v. 60, n. 03, p. 329-339, 2001. 60

VIGITEL, B. Vigilância de Fatores de Risco e Proteção para Doenças Crônicas Não Transmissiveis por meio de Inquérito Telefônico. 2014. 11

VOGLER, G. P. et al. Influences of genes and shared family environment on adult body mass index assessed in an adoption study by a comprehensive path model. International journal of obesity and related metabolic disorders: journal of the International Association for the Study of Obesity, v. 19, n. 1, p. 40-45, 1995. 27

WADA, R.; TEKIN, E. Body composition and wages. Economics $\&$ Human Biology, Elsevier, v. 8, n. 2, p. 242-254, 2010. 21, 25, 26

WOOLDRIDGE, J. M. Econometric analysis of cross section and panel data. [S.1.]: MIT press, 2010. 37 